\title{
SpaceLiner Technical Progress and Mission Definition
}

\author{
Martin Sippel, Tobias Schwanekamp, Olga Trivailo, Alexander Kopp, Carola Bauer, Nicole Garbers \\ Space Launcher Systems Analysis (SART), DLR, Bremen, Germany
}

DLR's launcher systems analysis division is investigating since a couple of years a visionary, extremely fast passenger transportation concept reaching the edges of space based on rocket propulsion. Thanks to multinational collaboration, the technical lay-out of the SpaceLiner has now matured to Phase A conceptual design level. Iterative sizing of all major subcomponents in nominal and off-nominal flight conditions has been performed.

The paper describes the recent technical progress achieved in the SpaceLiner 7 configuration,

- mainly system aspects of the reference vehicle's preliminary design including establishment of a preliminary structural concept,

- main propulsion system definition,

- pre-development of a passenger cabin and rescue capsule and its specific challenges,

- preliminary sizing of the thermal protection and active cooling systems,

- mission definition with its nominal trajectories including potential ground infrastructure,

- programmatic development aspects

$\begin{array}{ll}\text { CAD } & \text { computer aided design } \\ \text { GLOW } & \text { Gross Lift-Off Mass } \\ \text { LH2 } & \text { Liquid Hydrogen } \\ \text { LOX } & \text { Liquid Oxygen } \\ \text { NPSP } & \text { Net Positive Suction Pressure } \\ \text { MECO } & \text { Main Engine Cut Off } \\ \text { MR } & \text { mixture ratio } \\ \text { RCS } & \text { Reaction Control System } \\ \text { RLV } & \text { Reusable Launch Vehicle } \\ \text { SLME } & \text { SpaceLiner Main Engine } \\ \text { TPS } & \text { Thermal Protection System } \\ \text { TRL } & \text { Technology Readiness Level }\end{array}$

\section{Introduction}

A strategic vision of DLR which ultimately has the potential to enable sustainable low-cost space transportation to orbit is under technical evaluation since a couple of years. The number of launches per year should be strongly raised and hence manufacturing and operating cost of launcher hardware should dramatically shrink. The obvious challenge of the vision is to identify the very application creating this new, large-size market.

Ultra long distance travel from one major business center of the world to another major agglomeration on earth is a huge and mature market. Since the termination of Concorde operation, intercontinental travel is restricted to lowspeed, subsonic, elongated multi-hour flight. An interesting alternative to air-breathing hypersonic passenger airliners in the field of future high-speed intercontinental passenger transport vehicles is a rocket-propelled, suborbital craft. Such a new kind of 'space tourism' based on a two stage RLV has been proposed by DLR under the name SpaceLiner [1]. Ultra long-haul distances like Europe - Australia could be flown in 90 minutes. Other interesting intercontinental destinations between e.g. East-Asia and Europe or the Trans-Pacific-route to North-West America could be reduced to flight times of slightly more than one hour [22, 26].

Ultra-fast transportation far in excess of supersonic and even potential hypersonic airplanes is definitely a fundamental new application for launch vehicles. By no more than partially tapping the huge intercontinental travel and tourism market, production rates of RLVs and their rocket engines could increase hundredfold which is out of reach for all other known earth-orbit space transportation. The fast intercontinental travel space tourism, not only 
attracting the leisure market, would, as a byproduct, also enable to considerably reduce the cost of space transportation to orbit.

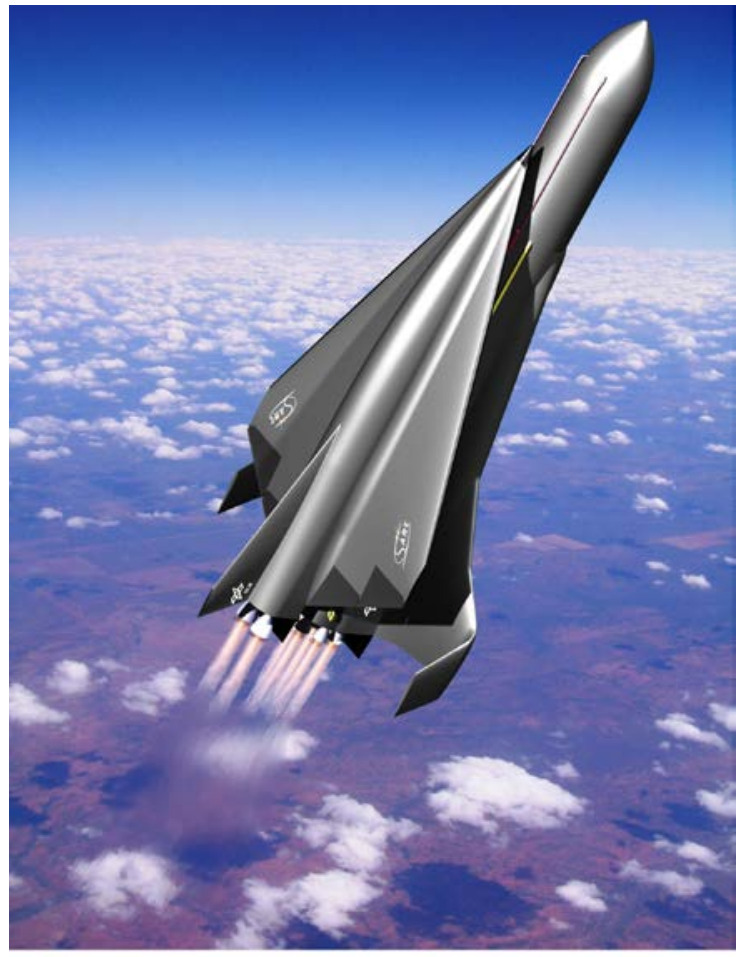

Figure 1: The SpaceLiner vision of a rocket-propelled intercontinental passenger transport is one of the most challenging projects in hypersonic research

The functionality of rocket propulsion is a proven technology since decades and their performance characteristics are well known. Furthermore, a rocket powered RLV-concept like the SpaceLiner is highly attractive because the flight durations are two to three times lower than those of even the most advanced airbreathing systems. Although additional times for travel are to be accounted, the actual time needed for travelling with the SpaceLiner might still be reduced by $75 \%$ to $80 \%$ compared to conventional subsonic airliner operation [6]. In contrast to the first generation of SST, thus a substantial advantage in travel times and hence improved business case can be expected.

An early assessment of the SpaceLiner's potential business case is described in the references 1, 2, and 5. A more detailed market analyses has been performed and results are published in [25, 26]. An operational scenario of the integrated door-to-door travel concept and the comparison with conventional intercontinental travel options are described in section IV.

\section{General Description of SpaceLiner concept}

\section{A. Status of Previous Technical Development}

First proposed in 2005 [1], the SpaceLiner is under constant development and descriptions of some major updates have been published since then $[2,14,10,26]$. The European Union's $7^{\text {th }}$ Research Framework Programme has supported several important aspects of multidisciplinary and multinational cooperation in the projects FAST20XX [17], CHATT [18, 19], HIKARI [20, 21], and HYPMOCES [42].

Different configurations in terms of propellant combinations, staging, aerodynamic shapes, and structural architectures have been analyzed. A subsequent configuration numbering has been established for all those types investigated in sufficient level of detail. The genealogy of the different SpaceLiner versions is shown in Figure 2. The box is marking the configuration trade-offs performed in FAST20XX in 2009/10.

These configuration studies supported the definition of the current reference configuration SpaceLiner 7. The designs of the interim research configurations $3,4,5$, and 6 , despite not fully studied in all details have been 
iteratively sized with careful scaling of the reference mass break-down, preliminary aerodynamic sizing and always trajectory optimization. An overview on these configurations can be found in [10].

At the end of 2012 with conclusion of FAST20XX the SpaceLiner 7 reached its first consolidated technical status [22, 26]. Several subsystems are sized and integrated, early operational scenarios are established, and cost and potential business cases are assessed. At the same time the design is further refined and meanwhile the third subversion called 7-3 is reached focused in this paper.

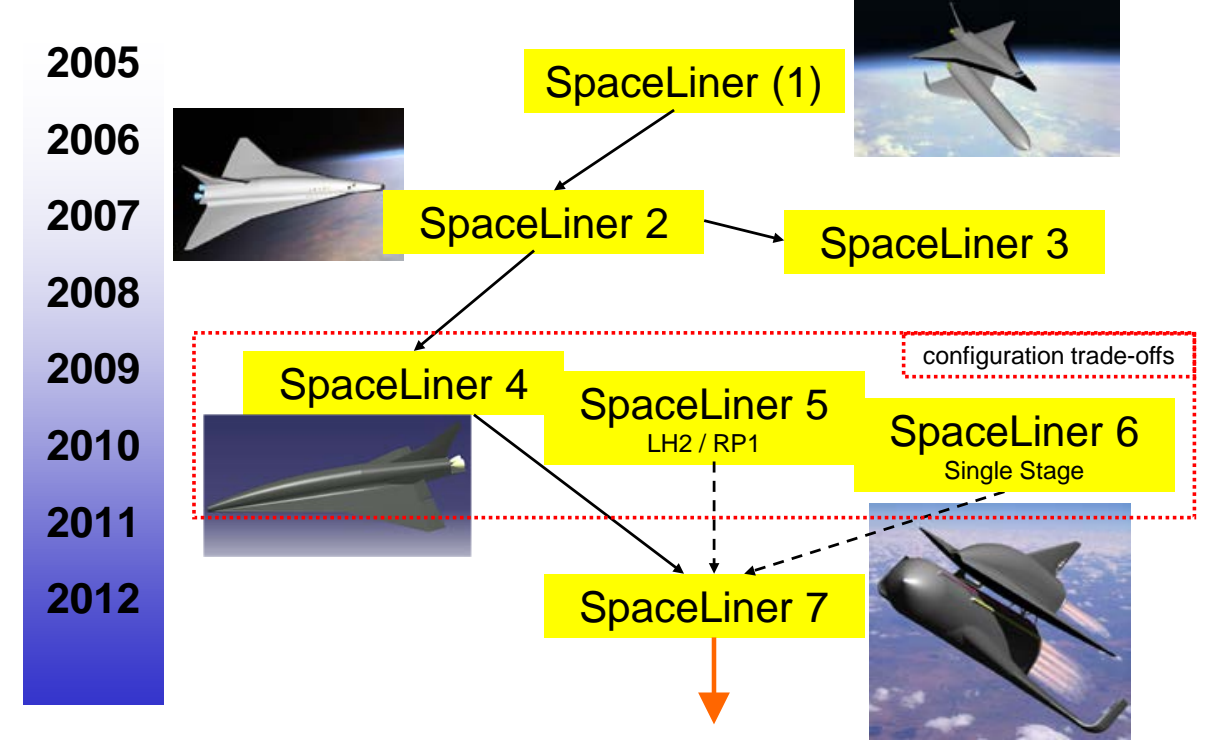

Figure 2: Evolution of the SpaceLiner concept

\section{B. Mission Definition}

The ambitious west-bound Australia - Europe mission has been used as the reference case since the beginning of the SpaceLiner investigations. This flight distance should be served for 50 passengers on a daily basis in each direction. Several other, shorter intercontinental missions exist, which potentially generate a larger market demand. For this reason a SpaceLiner configuration derivative has been studied, which could transport up to 100 passengers [37]. In order to keep the number of different stage configurations at the lowest possible level, the potentially interesting flight destinations have been divided into three classes:

- Class 1: Reference mission (up to $17000 \mathrm{~km}$ ) Australia - Europe with 50 passengers orbiter and large reference booster

- Class 2: Mission (up to $12500 \mathrm{~km}$ ) e.g. Dubai - Denver with increased 100 passengers orbiter and large reference booster

- Class 3: Mission (up to $9200 \mathrm{~km}$ ) e.g. Trans-Pacific with increased 100 passengers orbiter and reduced size booster

These three mission classes could be flexibly served by a suitable combination of four different vehicles (however with a lot of commonality in subcomponents like engines): 50 and 100 Passenger orbiter stage and large and shortened booster.

\section{Maturation to SpaceLiner 7-3}

Since the last hypersonic systems overview paper on the SpaceLiner [22] significant technical progress related to the overall launch configuration as well as to both stages, the reusable booster and the orbiter or passenger stage, has been achieved. The current arrangement of the two vehicles at lift-off is presented in Figure 3. Stage attachments are following a classical tripod design. The axial thrust of the booster is introduced through the forward attachment from booster intertank into the nose gear connection structure of the orbiter. The aft attachment takes all side and maneuvering loads. The option of a belly to belly connection is not preferred for two reasons: A strong unintended aerodynamic interaction of the two wings and propellant crossfeed lines on the booster which would be directly affected by hypersonic flow during reentry of this stage. All LOX-feedlines and the LH2-crossfeed connection are 
attached on the booster's top outer side, thus, subjected to flow in the relatively cold wake region. The feedlines of the upper stage are completely internal and ducted underneath the TPS. The arrangement in Figure 3 is the current baseline, however, it is still subject to trade-offs and optimization and hence might be changed in the future.

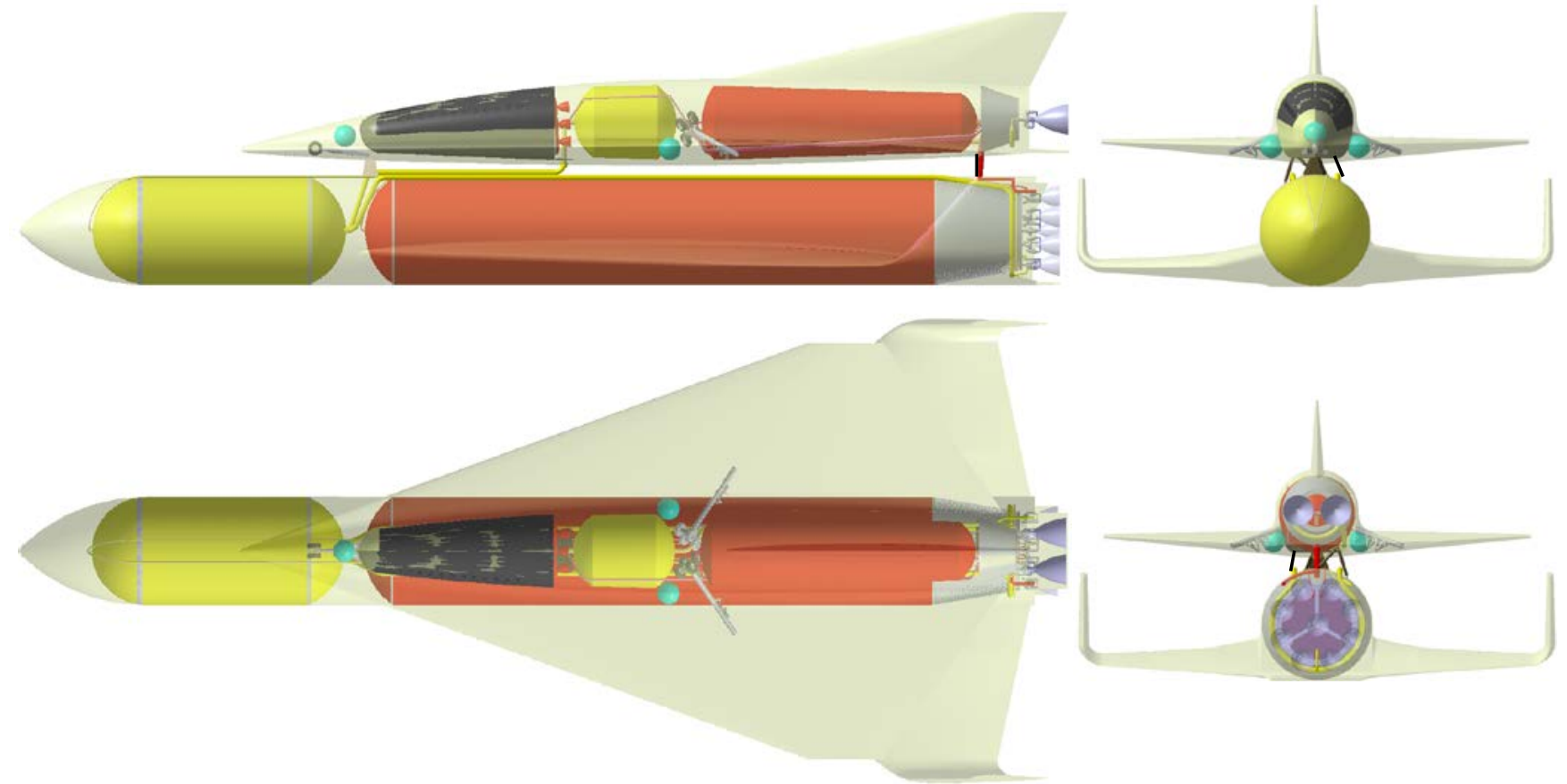

Figure 3: Sketch of latest SpaceLiner 7-3 launch configuration with passenger stage on top and booster stage at bottom position

\section{Definition of reusable booster stage}

Since the beginning of the SpaceLiner investigations the reusable booster stage has always been somewhat in the shadow of the orbiter which is carrying the passengers and is experiencing the highest thermal loads and reaching maximum velocity and altitude. However, the booster is also a very high performance launch vehicle stage and critical to the overall success of the SpaceLiner configuration.

The separation Mach number of the reference mission is approximately 12.5 which is already too high for any powered fly-back with acceptable amount of on-board fuel. A down-range landing side, if available at all, is not attractive for logistical reasons. Therefore, the patented in-air-capturing method [31,32] should be used. The empty stage is to be captured during subsonic descent and subsequently towed back by an airplane and finally released for an autonomous gliding landing on a runway. In simulations of the SpaceLiner booster's reentry it is always assured that sufficient time for the in-air-capturing maneuver is available.

The current SpaceLiner 7 booster geometry is relatively conventional with two large integral tanks with separate bulkheads for LOX and LH2 which resembles the Space Shuttle External tank lay-out. The major additions to the ET are an ogive nose for aerodynamic reasons and for housing subsystems, the propulsion system, and the wing structure with landing gear. The shape update to configuration 7-2 included a larger and more complicated wing with long strakes which became necessary for aerodynamic reasons in low speed landing approach. The overall size of the booster is reaching significant dimensions of more than $80 \mathrm{~m}$ in length, if the ambitious reference mission is to be served. Recently another update of the booster has been defined based on extensive analyses of the propellant crossfeed system, pre-design of major structural parts like tanks, intertank and the thrust frame. Further, the size of the body flap and the geometry of the large wing were optimized. Major geometrical data of this configuration 7-3 are listed in Table 1.

The booster wing (and winglet) airfoils have been adapted from the previous version 7-2. A constant trailing edge thickness of $75 \mathrm{~mm}$ is chosen [40]. The original 4-digit NACA wing airfoils have been altered to a different geometry, delivering aerodynamic as well as structural advantages. The maximum thickness position on the chord line is moved backwards which is beneficial for drag reduction in the supersonic and hypersonic flow and at the 
same time allows for larger frame heights in those regions where the largest amount of the aerodynamic lift forces are introduced. The wing modifications also resulted in a constant trailing edge sweep.

The airfoil changes from configuration 7-2 to the latest 7-3 are from 4-digit NACA to modified NPL-EC/ECH cut at trailing edge thickness of $75 \mathrm{~mm}$ [40]. The shapes of the NPL airfoils were defined by algebraic formulae at the National Physical Laboratories in the UK. They comprise an elliptic forward portion (E) and a rear portion (C) which, in the case of $\mathrm{ECH}$, is replaced by a hyperbolic $(\mathrm{H})$ curve very near the trailing edge [38]. The changes of the wing airfoils to NPL resulted in a slight decrease of drag and improved L/D compared to the previous 4-digit NACA foil wing.

Table 1: Geometrical data of SpaceLiner 7-3 booster stage

\begin{tabular}{|c|c|c|c|c|c|c|}
\hline length [m] & span [m] & height [m] & $\begin{array}{c}\text { fuselage } \\
\text { diameter [m] }\end{array}$ & $\begin{array}{c}\text { wing leading } \\
\text { edge angles } \\
\text { [deg] }\end{array}$ & $\begin{array}{c}\text { wing pitch } \\
\text { angle [deg] }\end{array}$ & $\begin{array}{c}\text { wing dihedral } \\
\text { angle [deg] }\end{array}$ \\
\hline 82.3 & 36.0 & 8.7 & 8.6 & $82 / 61 / 43$ & 3.5 & 0 \\
\hline
\end{tabular}

The latest 7-3 configuration of the booster not only includes an improved wing but also a considerably updated mechanical architecture. Overall propellant loading is reduced by 13.5 tons compared to the previous 7-2 due to volumetric constraints to approximately $1270 \mathrm{Mg}$. The integral tanks have been positioned slightly upward of the centerline which allows attachment of TPS with increased thickness on the lower side of the vehicle without impacting the outer mold line. The bodyflap length is reduced with the more compact arrangement of the aft section and total stage length is slightly shortened (see Table 1).

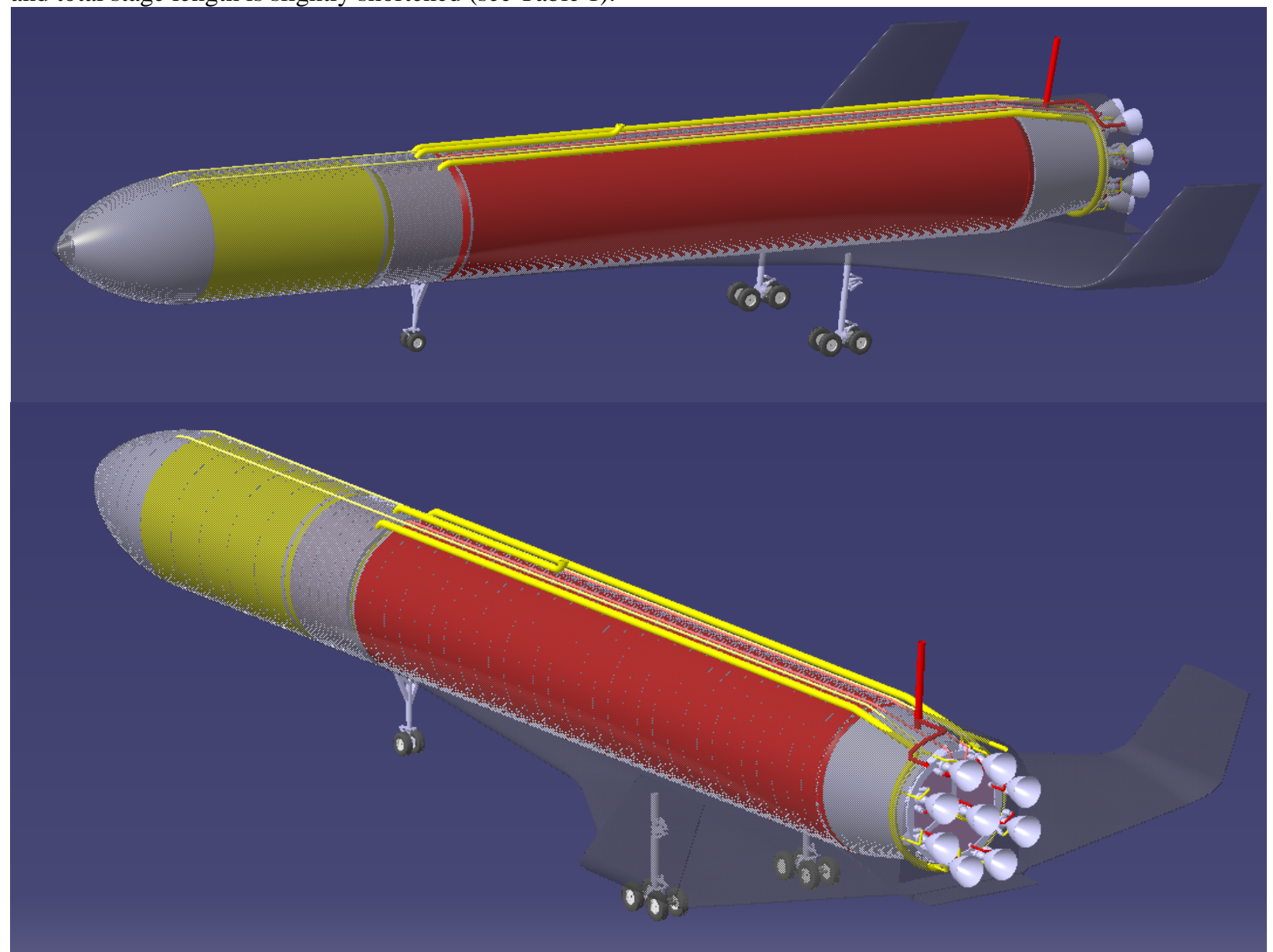

Figure 4: CAD-model of latest SpaceLiner 7-3 booster with semi-transparent outer surface showing internal arrangement of tanks and propellant feed- and pressurization-lines 
An early structural pre-dimensioning of the previous SpaceLiner 7-1 booster with similar fuselage but different wing had been performed at FOI in Sweden. The two tanks are part of the load carrying structure and therefore the structural members are placed internally. The structure of the wing follows aircraft convention with ribs to make up the shape of the wing profile and spars to carry the main bending load [22, 23, 26]. FOI's booster lay-out served as an initial conceptual model for future iteration of the SpaceLiner [23, 26]. The FOI structural design was not only looking into static load analyses but has been also addressing structural dynamic issues which are potentially critical for the feasibility of the design. A critical point was detected by Eigenmode analysis: The huge winglets were keeping the first few Eigenmodes of the wings below the global bending mode of the fuselage [22]. One option to improve the situation could have been repositioning the lateral stability surfaces to the fuselage. However, then an integration challenge for the launch configuration could have occurred.

The subsequent wing shape update to version 7-2 and then 7-3 completely changed its size and stiffness. Thus, the huge winglets remain in their original position at the wing tips. Both tanks with an external structural diameter of 8.5 $\mathrm{m}$ carry all major loads and interface thrust to the passenger stage is going through the intertank right in front of the very large LH2 tank with a total internal volume of $2577 \mathrm{~m}^{3}$. Engine thrust and the ground support loads at the launch pad are directed through the conical thrust frame shown in Figure 5 which is connected to the aft-Y-ring of the hydrogen tank.

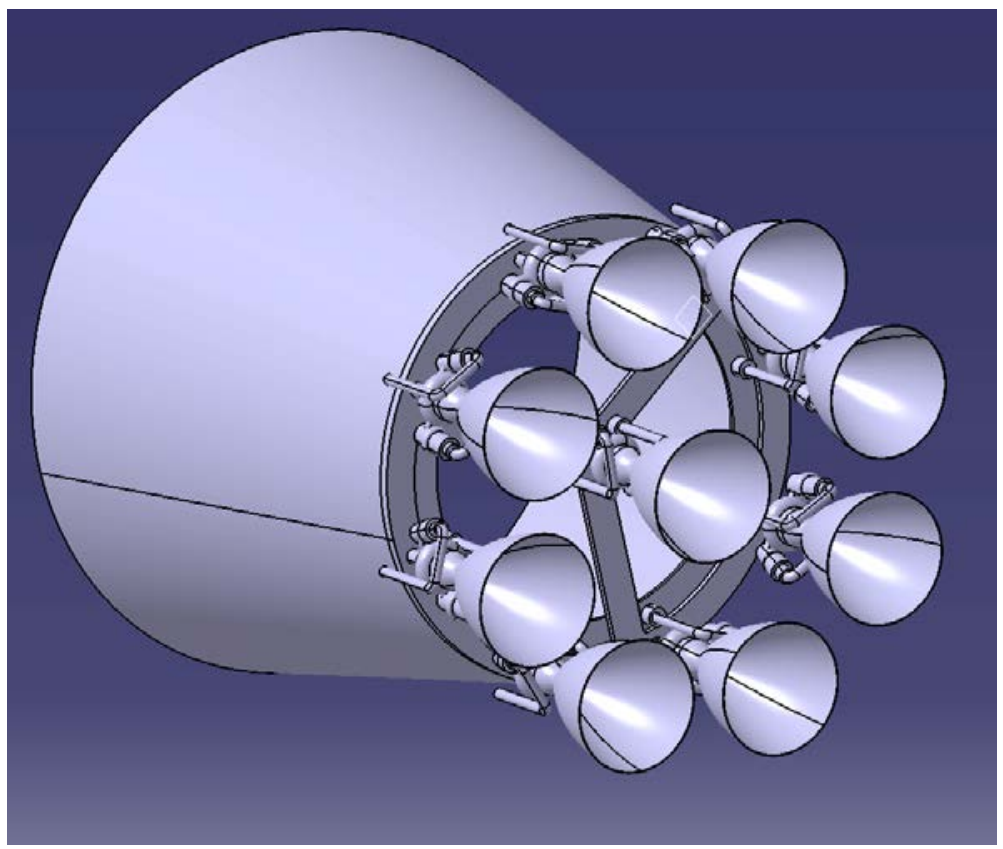

Figure 5: Thrust cone of SpaceLiner 7-3 booster with SLME attached

Recently, the main primary structure elements of the fuselage have been sized for dimensioning loads during powered ascent. The thrust frame is a conical structure strongly supported by frames and stringers and a center star segment. Both tanks are metallic aluminum-lithium structures, integrally stiffened by stringers and internally attached frames. The external loads, mainly those of the wing, are to be introduced in dedicated main frames of the hydrogen tank. The optimum connection between pressurized and unpressurized elements as well as cold cryogenic tanks and continuously warm construction is under study. A potentially interesting option could be a strut element design which has recently been investigated [27].

For analyses of the connective truss structure model, the Finite Element (FE) solver ANSYS has been used. The maximum ascent loads due to dynamic pressure and wind gust has been selected for the calculations. To solve for the stresses and displacements of the structure, initial cross sectional values for the trusses' radii have been assumed. Afterwards, an ANSYS optimization process has been used, to correctly size the truss structure to the model loads. This procedure only accounts for axial and bending stresses of the design variables and only failure criteria and minimum gauge thickness have been used. Additionally, buckling of the trusses has been considered according to Ballesrstedt and Wagner equation. Obtained stress levels of the truss connecting structure are shown in Figure 6. Aluminum struts with an outer diameter of $4 \mathrm{~cm}$ achieves the lowest total weight of less than $300 \mathrm{~kg}$ [27]. 


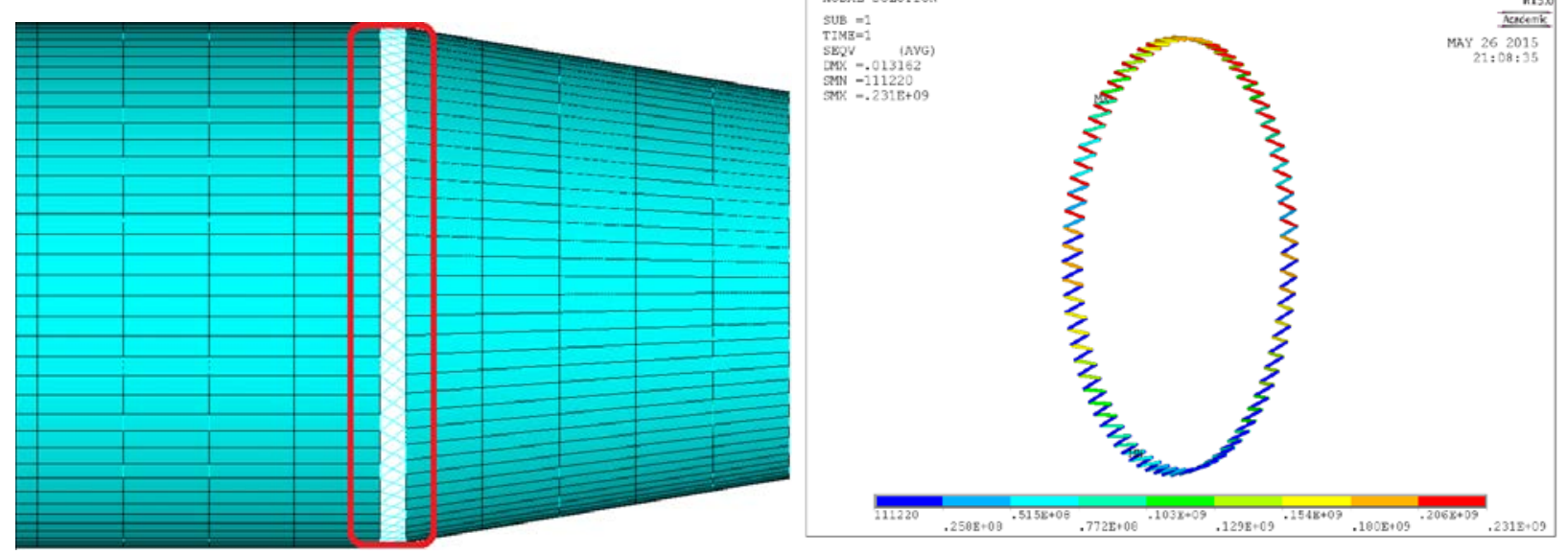

Figure 6: ANSYS-model of truss connection between thrust cone and hydrogen tank and FE-results [27]

\section{Evolution of the passenger stage}

The Mach number range of the SpaceLiner passenger stage stretches from the hypersonics through the transonic regime to the low speed subsonic landing approach. An extensive study on the different geometrical options for the optimization of the hypersonic aerodynamic and aerothermodynamic characteristics of the SpaceLiner has been concluded at DLR in 2010 [13].

The SpaceLiner7 is the first SpaceLiner configuration characterized by an aerodynamic shape arisen from a fully automated optimization process. In order to consider a wide range of the hypersonic trajectory, three points with different flight Mach numbers (20.1, 13.6, 6.0) and corresponding altitudes were chosen for the optimization [33]. A set of geometrical design parameters was released to variegate during the optimization process (nose radius, nose length, wing span, chord length, sweep angle, airfoil thickness) while a couple of geometrical and physical constraints were set (e.g. minimum lift, maximum stagnation point heat flux) [33]. In further adaptation the SpaceLiner 7-1's most striking difference is a trailing edge angle which affects the center of pressure position in a way that the pitching moment at maximum L/D hypersonic flight is close to its trimmed state without any control surface deflection. The vertical stabilizer is modeled with very large leading edge inclination.

The SpaceLiner Orbiter wing airfoils were slightly adapted for the latest 7-3 configuration to keep a finite minimum thickness at the trailing edges. For operational considerations and for practical TPS integration a $50 \mathrm{~mm}$ constant thickness is chosen. At the wing's root a modified NACA 66-003.5 is implemented which is cut when the trailing edge thickness reaches $50 \mathrm{~mm}$. At the wing tip a modified NACA 66-005.5 is cut at the same trailing edge thickness. Although the changes in trailing edge thickness are minor, having almost no impact on calculated aerodynamic performances, the fuselage-wing interface surface geometry with complicated 3D-shapes needed a redesign. The local curvature is carefully designed to avoid any potential hot spot areas. The latest SpaceLiner passenger stage shape is shown in Figure 7.

Safe controllability of the vehicle in all flight conditions has to be assured including during abort cases. To define the wing flaps of the SpaceLiner, knowledge on the most extreme flight maneuvers is needed. This has been assumed to be an abort scenario starting at the time of booster separation with the passenger stage's propulsion system inoperative. A re-entry trajectory for this case is simulated with the constraint of maximal allowed loads [15]. The wing flaps are following this sizing approach. The flap's hinge line attachment is influenced by the Space Shuttle example. The overall design is promising but will still require a more detailed assessment of efficiency and aerothermodynamic issues in the future.

For the descent flight of the orbiter stage the most detailed aerodynamic analyses of all configurations were conducted yet. In addition to fast empirically derived assessment, a panel code, and surface inclination methods also CFD (Euler) simulations were performed from subsonic to hypersonic Mach numbers. ESA has been calculating the shape of the SpaceLiner 7-1 passenger stage in 2012 with Euler CFD [22, 40]. Obtained coefficients have been used in support for establishing the aerodynamic data base. In the hypersonic flight regime these CFD lift and drag data 
are in very good agreement with those of engineering methods previously generated by DLR [28] which justifies the programs used in the aerodynamic optimization process mentioned in [33].

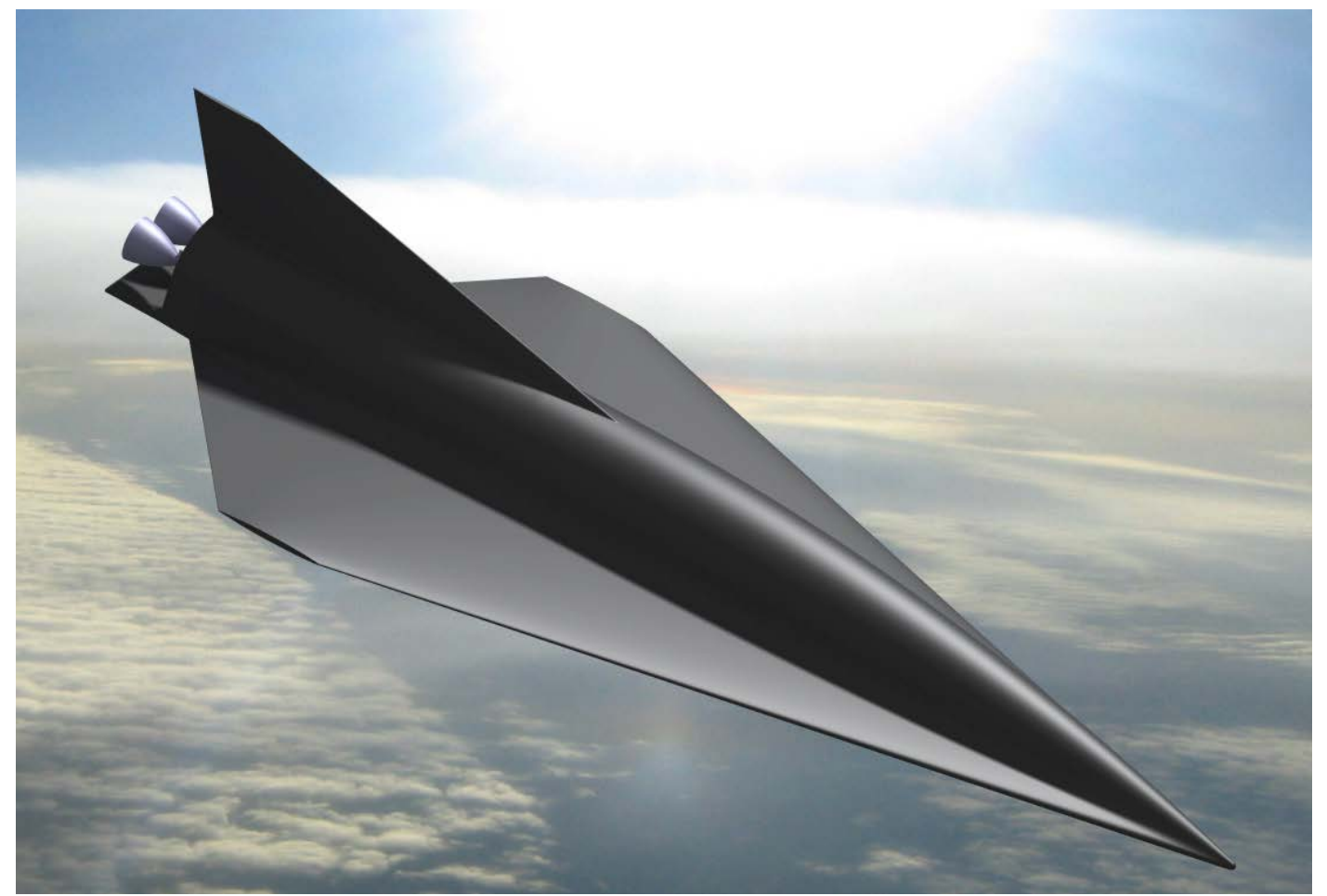

\section{Figure 7: SpaceLiner 7-3 passenger stage}

The SpaceLiner 7 passenger stage achieves without flap deflection an excellent hypersonic L/D of 3.5 up to M=14 assuming a fully turbulent boundary layer. The laminar-turbulent transition is assumed occurring at an altitude of 58 $\mathrm{km}$ which is around Mach 18 [40]. Impact of the finite trailing edge of version 7-3 on aerodynamic efficiency is negligible.

Major geometry data of the SpaceLiner 7-3 passenger stage are summarized in Table 2.

Table 2: Geometrical data of SpaceLiner 7-3 passenger stage

\begin{tabular}{|c|c|c|c|c|c|c|}
\hline length [m] & span [m] & height [m] & $\begin{array}{c}\text { fuselage } \\
\text { diameter [m] }\end{array}$ & $\begin{array}{c}\text { wing leading } \\
\text { edge angle } \\
\text { [deg] }\end{array}$ & $\begin{array}{c}\text { wing Pitch } \\
\text { angle [deg] }\end{array}$ & $\begin{array}{c}\text { wing } \\
\text { Dihedral } \\
\text { angle [deg] }\end{array}$ \\
\hline 65.6 & 33.0 & 12.1 & 6.4 & 70 & 0.4 & 2.65 \\
\hline
\end{tabular}

Preliminary structural analyses have been conducted for the SpaceLiner orbiter. The ANSYS based structural analysis system HySAP developed at DLR-SART has been used, which iteratively adapts the structural dimensions in order to minimize the vehicle mass. Detailed tool descriptions can be found in [35]. The considered load cases include $2.5 \mathrm{~g}$ and $-1.0 \mathrm{~g}$ normal acceleration manoeuvres with flap deflection, rocket powered ascent where the orbiter is still attached to the booster, and landing loads at main gear touch-down.

The vehicle structure is an all honeycomb-sandwich design. Stringer stiffening has been investigated as well, but found to be not competitive due to the dominance of bi-axial stress systems in many panels. Several structural materials have been compared with each other. Thermal effects in terms of material property degradation and thermal stresses have been included in the analysis. Thereby, the wing and fuselage skins operate at elevated temperatures, which correspond to the structural temperature limits for which the particular TPS was designed. As a worst case scenario, the internal members (ribs, spars, frames) are assumed to remain at room temperature (293 K) resulting in temperature gradients which induce significant thermal stresses. This reflects the strong transient heating environment due to rapid heat flux build-up in the first part of the trajectory. 
The cut-out in the fuselage necessary for passenger cabin integration are included in the vehicle's FE-model. Figure 8 exemplarily shows stress resultants in $\mathrm{x}$ - and $\mathrm{y}$-direction in the local panel coordinate systems for the landing load case. The vehicle deflections are exaggerated in the figure. Severe local loads in the cut-out area are obvious, which explains the structural mass increase. Stress resultant peaks can also be observed at the landing gear positions in the wing due to touch down load introduction.
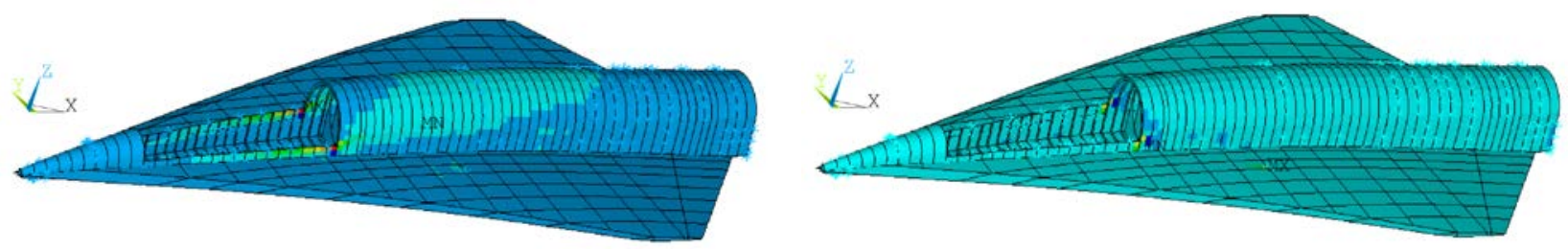

Figure 8: Stress resultants in $\mathrm{x}$-direction (left) and y-direction (right) in local panel coordinate systems for landing load case for SpaceLiner 7-3 primary structure

A structural mass comparison for different materials has been performed and preliminary results are presented in comparison to a statistically based estimation (STSM) in Figure 9. Structural skin temperature levels of $293 \mathrm{~K}, 400$ $\mathrm{K}, 480 \mathrm{~K}$, and $530 \mathrm{~K}$ have been investigated which reflects the temperature levels for which different TPS designs have been generated. Investigated materials include the standard aluminium alloys 2014 and 2024, aluminiumlithium 2195, titanium, beryllium based LockAlloy. The PETI-based high-temperature composite IM7/PETI-5 delivers the lightest solution. Note that this materials temperature range has been slightly extended to $520 \mathrm{~K}$ in the calculation although [36] states that the maximum operation temperature of this material is limited to around $505 \mathrm{~K}$ $\left(450^{\circ} \mathrm{F}\right)$. An interesting trend is observable for the titanium vehicle structure, which - in contrast to the results for the simplified model - does not anymore exhibit a structural mass increase with increasing temperature. This is presumably a result of load-redistributions due to the strong coupling between wing and fuselage.

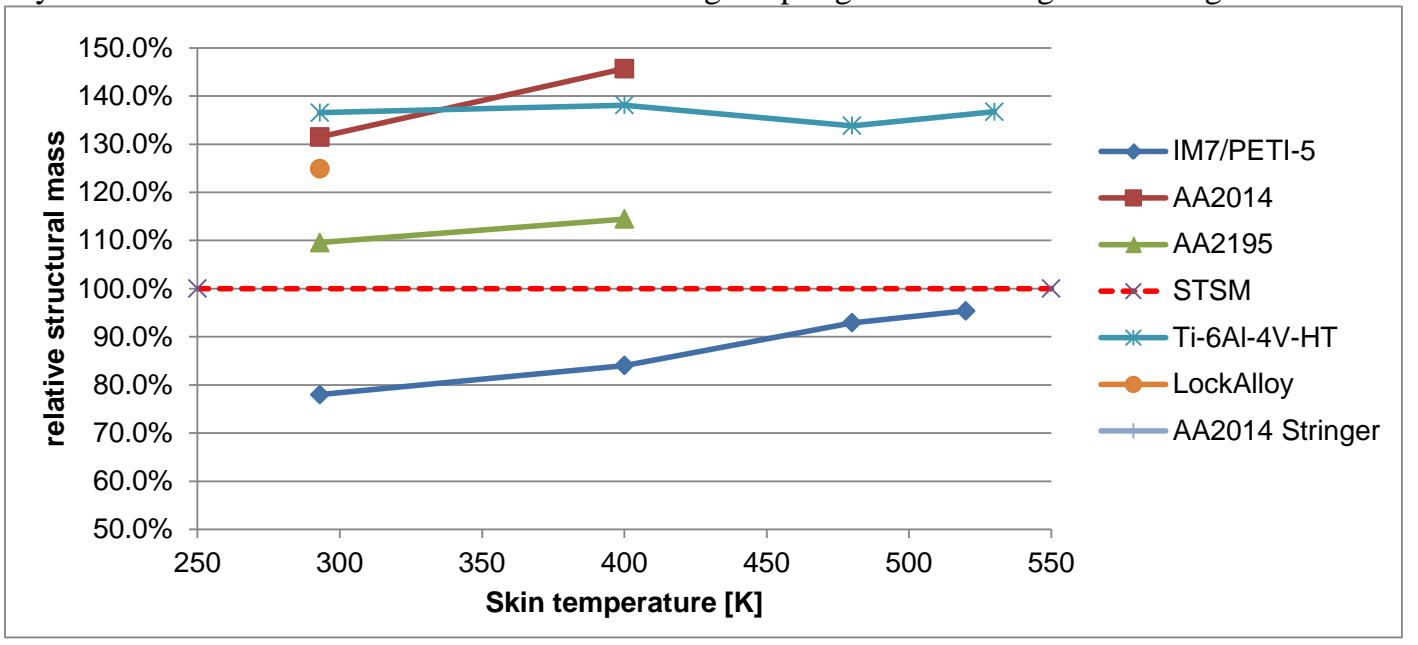

Figure 9: Relative structural masses (wing plus fuselage) for SpaceLiner7 passenger stage as function of skin temperature and material choice

These analyses do not yet consider the TPS integration which will result in a structural mass increase. Overall tendencies for the different materials are expected to remain similar.

\section{E. Subsystem definitions}

In the EC-funded projects FAST20XX, CHATT, and HYPMOCES several SpaceLiner subsystems are preliminarily defined and evaluated. The following sections summarize the recent progress.

1. Main propulsion system

Staged combustion cycle rocket engines with a moderate 16 MPa chamber pressure have been selected as the baseline propulsion system right at the beginning of the project [1]. Two types of staged combustion cycles (one full-flow and the other fuel-rich) have been considered for the SLME and traded by numerical cycle analyses [16]. A Full-Flow Staged Combustion Cycle with a fuel-rich preburner gas turbine driving the LH2-pump and an oxidizer- 
rich preburner gas turbine driving the LOX-pump is a preferred design solution for the SpaceLiner. This approach should allow avoiding the complexity and cost of additional inert gases like Helium for sealing.

In a Full-Flow Staged Combustion Cycle (FFSC), two preburners whose mixture ratios are strongly different from each other generate turbine gas for the two turbo pumps. All of the fuel and oxidizer, except for the flow rates of the tank pressurisation, is fed to the fuel-rich preburner (FPB) and the oxidizer-rich preburner (OPB) after being pressurised by each turbo pump. After the turbine gas created in each preburner work on each turbine they are all injected in hot gaseous condition into the main combustion chamber (MCC). The regenerative cooling of the chamber and the nozzle is made with hydrogen fuel after being discharged by the FTP. The fuel tank pressurization gas is supplied from the fuel line after leaving the regenerative circuit while the oxidizer tank pressurization gas is bled from the oxidizer line behind the OTP discharge and then heated-up in a heat exchanger [16].

The expansion ratios of the booster and orbiter engines are adapted to their respective optimums; while the mass flow, turbo-machinery, and combustion chamber are assumed to remain identical in the baseline configuration.

The SpaceLiner 7 has the requirement of vacuum thrust up to $2350 \mathrm{kN}$ and sea-level thrust of $2100 \mathrm{kN}$ for the booster engine and $2400 \mathrm{kN}, 2000 \mathrm{kN}$ respectively for the passenger stage. All these values are given at a mixture ratio of 6.5 with a nominal operational MR-range requirement from 6.5 to 5.5 .

The SpaceLiner's ascent reference mission requirements define engine cycle times per flight [29]:

- Nominal operation time of Booster engine: 245 s with 122 s @ MR=6.5 and 122 s @ MR=5.5 or earlier cutoff

- Nominal operation time of Passenger Stage engine: 463 s with 336 s @ MR=6.5 and 127 s @ MR=5.5

The average engine life-time should be 25 missions. Table 3 gives an overview about major SLME engine operation data for the nominal MR-range as obtained by cycle analyses.

Table 3: SpaceLiner Main Engine (SLME) technical data [29]

\begin{tabular}{|l|c|c|c|c|c|c|}
\hline & \multicolumn{3}{|c|}{ Booster } & \multicolumn{3}{c|}{ Passenger Stage } \\
\hline Mixture ratio [-] & 5.5 & 6.0 & 6.5 & 5.5 & 6.0 & 6.5 \\
\hline Chamber pressure [MPa] & 15.1 & 16.0 & 16.9 & 15.1 & 16.0 & 16.9 \\
\hline Fuel-rich Preburner pressure [MPa] & 29.4 & 30.0 & 30.8 & 29.5 & 30.2 & 31.0 \\
\hline Oxidizer-rich Preburner pressure [MPa] & 29.1 & 29.7 & 30.5 & 29.2 & 29.9 & 30.7 \\
\hline Fuel-rich Preburner TET [K] & 732 & 735 & 738 & 720 & 722 & 724 \\
\hline Oxidizer-rich Preburner TET [K] & 773 & 775 & 778 & 772 & 774 & 777 \\
\hline Expansion ratio [-] & 33 & 33 & 33 & 59 & 59 & 59 \\
\hline Specific impulse in vacuum [s] & 439 & 437 & 435 & 451 & 449 & 448 \\
\hline Specific impulse at sea level [s] & 387 & 389 & 390 & 357 & 363 & 367 \\
\hline Thrust in vacuum per engine [kN] & 2061 & 2206 & 2356 & 2116 & 2268 & 2425 \\
\hline Thrust at sea level per engine[kN] & 1817 & 1961 & 2111 & 1678 & 1830 & 1986 \\
\hline
\end{tabular}

The engine performance data are not overly ambitious and have already been exceeded in the past by existing engines like SSME or RD-0120. However, the ambitious goal of a passenger rocket is to considerably enhance reliability and reusability of the engines beyond the current state of the art. The mixture ratios of FPB and OPB are controlled so that TET is restricted to around $770 \mathrm{~K}$. At each turbine a bypass line is foreseen for which the flow should be controlled by a hot gas valve in order to allow engine operation in the mixture ratio range from 5.5 to 6.5 without changing TET or excessively raising pre-burner pressures. Further, this approach gives some margin to significantly raise engine power in case of emergency by increasing TET beyond the limitation [16].

Cycle analyses results for the full-flow have been used for preliminary turbo-machinery sizing. An Integrated Power Head (Pre-burner + Turbine + Impeller pump) as used on the SSME is the preferred design solution for the SLME. The reduced length of high pressure hot gas lines should enable significant mass saving and a compact and clean lay-out. The size of the SLME in the smaller booster configuration is a maximum diameter of $1800 \mathrm{~mm}$ and overall length of $2981 \mathrm{~mm}$. The larger passenger stage SLME has a maximum diameter of $2370 \mathrm{~mm}$ and overall length of 
$3893 \mathrm{~mm}$. A size comparison of the two variants and overall arrangement of the engine components is visible in Figure 10.

The engine masses are estimated at $3375 \mathrm{~kg}$ with the large nozzle for the passenger stage and at $3096 \mathrm{~kg}$ for the booster stage. These values are equivalent to vacuum T/W at MR=6.0 of 68.5 and 72.6.

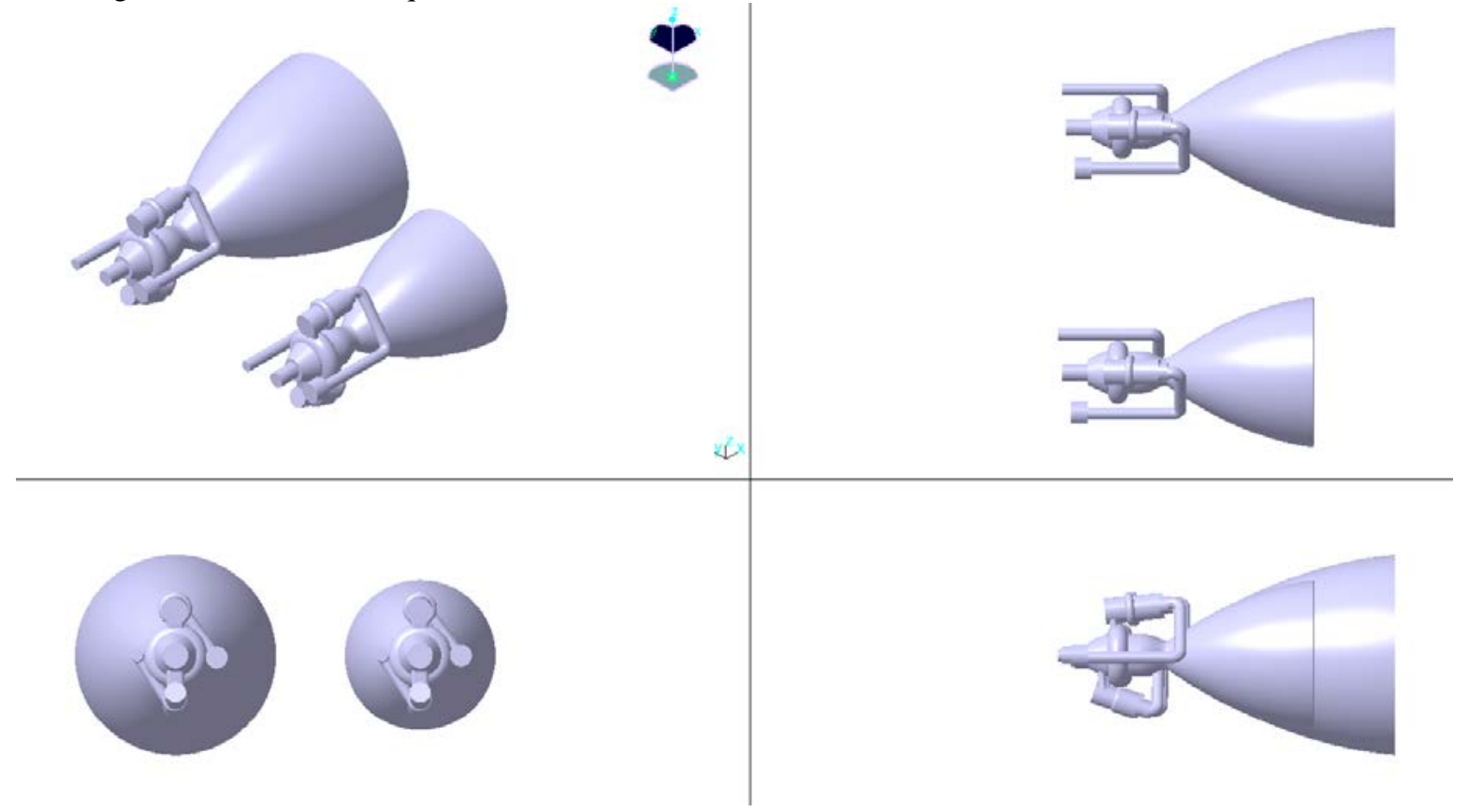

Figure 10: Size comparison of simplified CAD-shapes of SLME with $\varepsilon=33$ and $\varepsilon=59$

\section{Propellant feed and tank pressurization system}

All main engines of the configuration should work from lift-off until MECO. A propellant crossfeed from the booster to the passenger stage is foreseen up to separation to reduce the latter's overall size. No crossfeed system for a configuration like the SpaceLiner has ever been built and therefore investigations have been performed to determine how such a system could be implemented and how complexity issues can be addressed.

Three main options of crossfeed exist:

- Line-to-line

- Tank-to-tank

- Tank-to-buffer-tank

These options have been investigated in the project CHATT with steady-state flow-simulation along the full powered trajectory and transient simulation of critical phases like crossfeed valve closing. In particular, the process of booster separation is a dimensioning factor for the design of the crossfeed system due to the switch of the propellant supply from the booster to the orbiter tanks [30]. The propellant feed- and pressurization system is preliminarily designed using the DLR-tool pmp. The SpaceLiner 7-3 arrangement of feed- and pressurization lines with the tanks of both stages in the mated configuration is shown in Figure 11. All other structural elements than tanks and lines are excluded from the picture for clarity.

The steady-state simulation results from PMP for the feedline pressure during the ascent on LOX and LH2-side are visible in Figure 12. A tank to tank crossfeed from the booster LOX-tank, positioned more than $25 \mathrm{~m}$ forward, generates significant hydrostatic pressure, indirectly forcing ullage pressure in the second stage tank up to more than 6 bar. Further downstream in the feedline pressure values can exceed 15 bar. The effects of throttling and staging are clearly visible in Figure 12. NPSP at the LOX-turbopump entry is generous and might allow for reducing the ullage pressure close to MECO. On the LH2-side NPSP is close to its lower limit. As a consequence of the additional valves and hence pressure losses compared to the previous design, the NPSP at the LH2 entry of the orbiter engine turbopumps would fall below acceptable values during the crossfeed operation phase. Hence, the ullage pressure in the booster LH2 tank had to be increased to $340 \mathrm{kPa}$. 


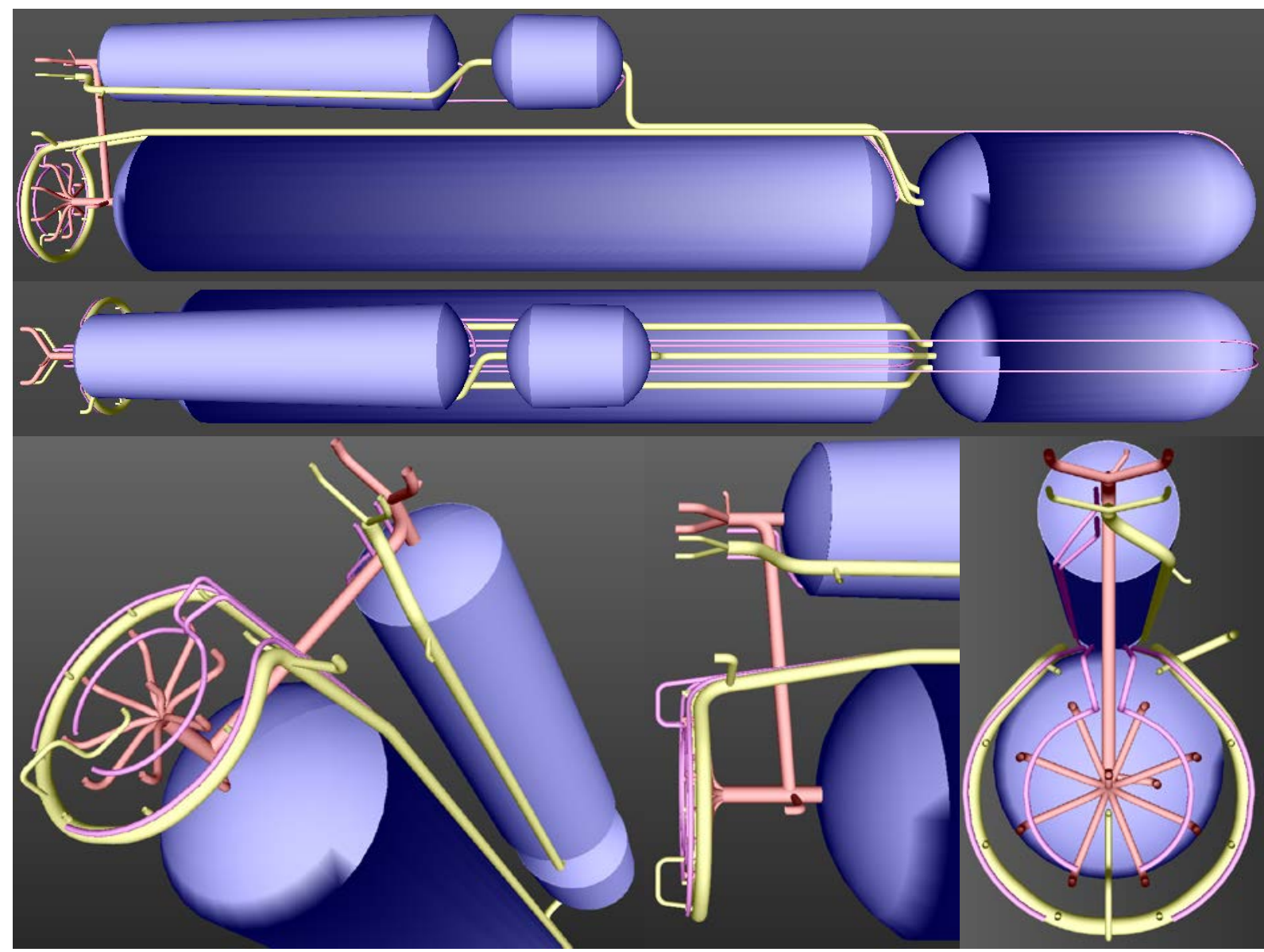

\section{Figure 11: Feedline design of the SpaceLiner 7-3}
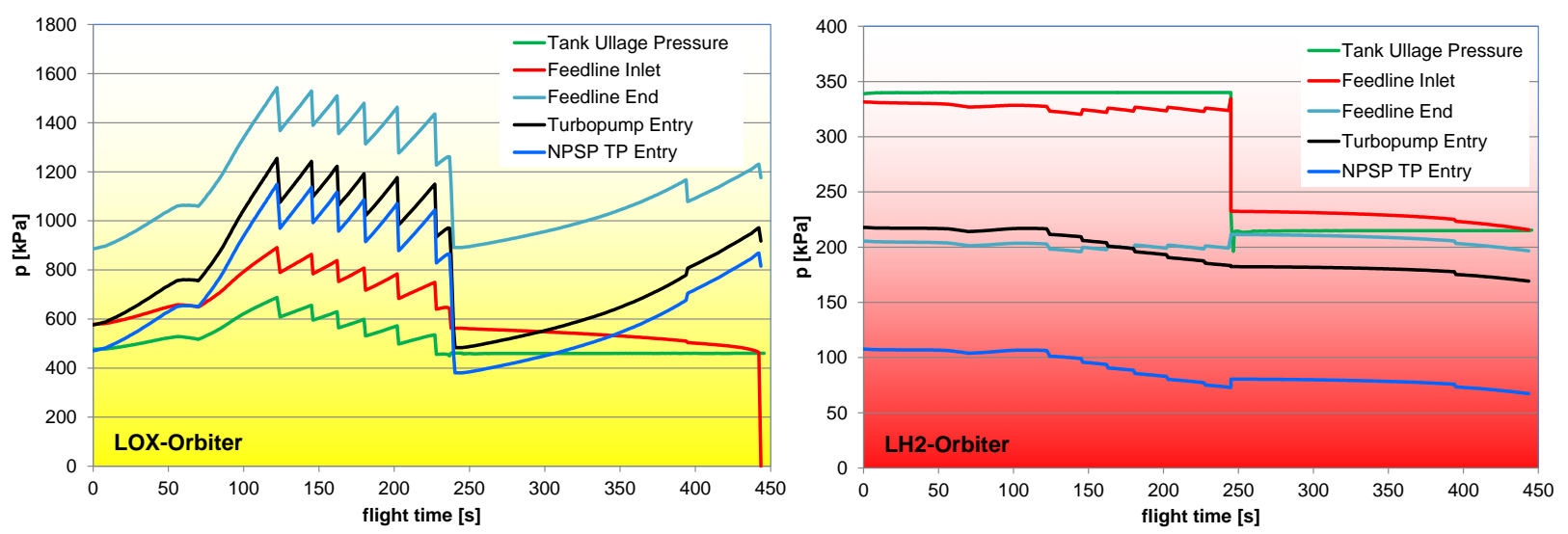

Figure 12: Pressure at certain stations of the SpaceLiner 7-3 orbiter propellant system, crossfeed is active until stage separation at $244.9 \mathrm{~s}$

Beyond the steady state simulation also the transient behavior in the propellant feed-system has been analyzed for critical conditions along the powered flight and its preferred actuation sequence has been preliminarily defined [30].

The LOX-tanks are pressurized by gaseous oxygen and the hydrogen tanks with gaseous hydrogen. This approach is selected in order to avoid any excessive use of expensive and rare helium. The fuel tank pressurization gas is supplied from the SLME after leaving the regenerative circuit while the oxidizer tank pressurization gas is bled from the oxidizer line behind the OTP discharge and then heated-up in a heat exchanger. 
Tank pressures are selected that the minimum NPSP requirements in all feedline segments are respected along the full mission; especially those at the engine entry. The booster LOX tank pressure has been further reduced to just 1 bar differential pressure to the external conditions because its forward position is always generating a lot of hydrostatic pressure down the line which is beneficial for good NPSP. Due to this fortunate situation, the required oxygen gas at booster stage MECO is considerably below $3000 \mathrm{~kg}$. The hydrogen gas mass inside the very large $2577 \mathrm{~m}^{3}$ LH2-tank is currently slightly below $3400 \mathrm{~kg}$ due to the increase in ullage pressure requirement; however still acceptable because of hydrogen's low molecular mass.

For the LOX system, the tank-to-tank crossfeed approach is definitely recommended, because the LOX-transport is supported by the hydraulic head of the booster tank's forward position. Almost no transient critical issues have been found. If the line-to-line architecture will be used for LH2, the particular focus has to be on the valve timing and control. For the latest SpaceLiner 7-3 configuration line-to-line crossfeed for LH2 and tank-to-tank crossfeed for the LOX system is the baseline choice.

\section{Cabin and rescue system}

The passenger cabin of the SpaceLiner has a double role. Providing first a comfortable pressurized travel compartment which allows for horizontal entrance of the passengers, the cabin in its second role serves as a reliable rescue system in case of catastrophic events. Thus, the primary requirements of the cabin are the possibility of being firmly attached late in the launch preparation process and fast and safely separated in case of an emergency.

The capsule is able to fly autonomously back to Earth's surface in all separation cases. The abort trajectories are primarily influenced by the mass of the capsule and the aerodynamic performance with the most important subsystems being the separation motors, the thermal protection system (TPS), and the structure. These three subsystems have been recently investigated and sized for function, performance, and mass.

Four critical points are chosen to simulate the abort trajectory to demonstrate the SpaceLiner7 capsule is able to fly safely back to Earth during any perceived abort scenario:

- Launch pad

- Booster separation

- Highest altitude of the SpaceLiner7 orbiter

- Main engine cut-off (MECO)

Results of the trajectory simulations are presented in [34, 44].

The separation motors are designed to separate the capsule from the orbiter, without exceeding recommended maximum acceleration limits. The following requirements are considered:

- reliability in performance

- ability to reach a safe distance in a short period of time

- ability to reach a certain altitude

- requirement to fit within the SpaceLiner7 orbiter

In order to fulfill these requirements, a high acceleration is to be provided in a very short period of time by a solid motor. Due to severe geometry constraints, it has been decided to utilize a five motor configuration. With a chamber pressure of $150 \mathrm{bar}$, an expansion ratio of 25 and a half angle of $15^{\circ}$, the length of the nozzle is slightly under $1 \mathrm{~m}$ and the entire length of one motor is approximately $1.4 \mathrm{~m}$. The motor has an approximate thrust of $800 \mathrm{kN}$ and a burn time of almost $2 \mathrm{~s}$ while the total mass of the propellant for all five motors adds up to $2.6 \mathrm{t}$ [34].

The Thermal Protection System (TPS) of the SpaceLiner7 capsule is required to withstand several different heat loads according to the different nominal and abort cases it encounters. In the course of this investigation, it has to be distinguished which areas of the capsule (i.e. the nose area, upper half or lower half) are considered. During nominal flight, the capsule is considered part of the orbiter. This means that the lower half and nose are protected by the orbiter structure and its TPS. They are therefore, not subjected to the external heat load until the capsule is separated in an abort case. In contrast, the capsule's upper half is part of the orbiter's outer shell and so is heated up during nominal flight. These differences lead to different starting conditions regarding initial temperature after abort separation. 
A potential cabin pre-design and the necessary life-support system mostly driven by medical requirements have been studied. Absolutely essential is a small shell-like protection around each seat which would automatically close in case of sudden cabin pressure drop.

Overall length of the capsule without separation motors is $15.6 \mathrm{~m}$ and its maximum external height is $5.6 \mathrm{~m}$. The estimated masses are slightly less than 30 tons for the dry capsule, about $7900 \mathrm{~kg}$ for the passengers, crew and luggage, and $3400 \mathrm{~kg}$ for all propellants of separation motor and RCS. The RCS propellants could also partly be used in the nominal mission of the SpaceLiner. The capsule's configuration resulting from work in FAST20XX is depicted in Figure 13.
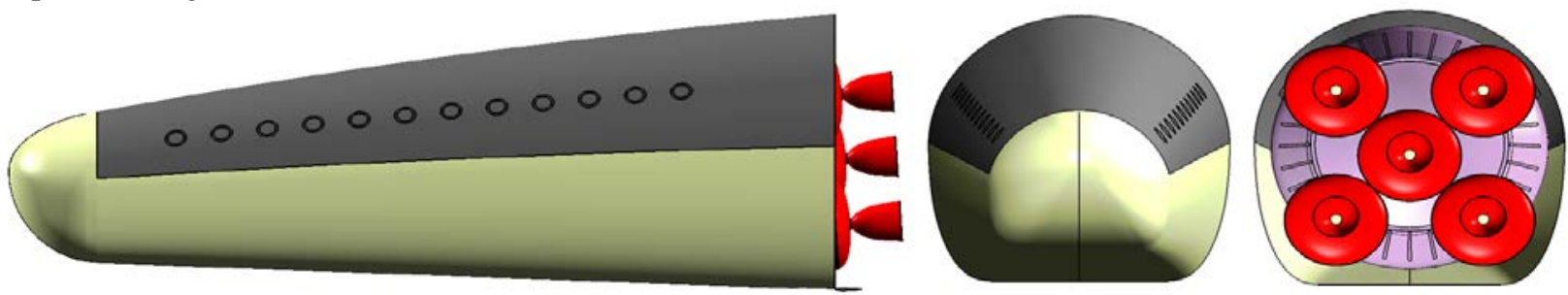

Figure 13: SpaceLiner7 reference passenger capsule design in side-, front-, and aft-view

Orbspace has been in charge of the structural assessment of the passenger capsule to obtain its conceptual structural design, in particular with respect to the window design, which is considered a critical vehicle subsystem. The main structure consists of a conical pressure vessel with a cone angle of about $12^{\circ}$. The nose is closed with a spherical bulkhead of $3100 \mathrm{~mm}$ diameter, and the rear with a convex tori-spherical bulkhead. The pressurized cabin is made of Al2219 T87. The three dominant load cases of the capsule are the cabin pressure and the loads from the thrust of the separation rocket motors in axial and normal direction. The latter are generating axial and bending loads. FE analyses have been carried out [26].

Based on the results of the analyses presented in [34], an axi-symmetric (conic) structural concept has been chosen for the pressurized cabin. In the following step of structural assessments, the structural response to the loads during the firing of the escape ejection motor has been addressed. The combined thrust of all escape ejection motors is in the order of $4000 \mathrm{kN}$. This subjects the passenger capsule in extreme emergencies to an acceleration of about $10 \mathrm{~g}$ for approximately 2s. A thrust frame consisting of a cone, a ring frame and a cross-beam has been chosen to distribute these high thrust loads uniformly into the main vehicle structure. The structure itself has also been stiffened by a number of stringers and frames. The load case for the launch site abort has been chosen, because there is no differential pressure across the cabin wall which would provide a positive stiffening effect.
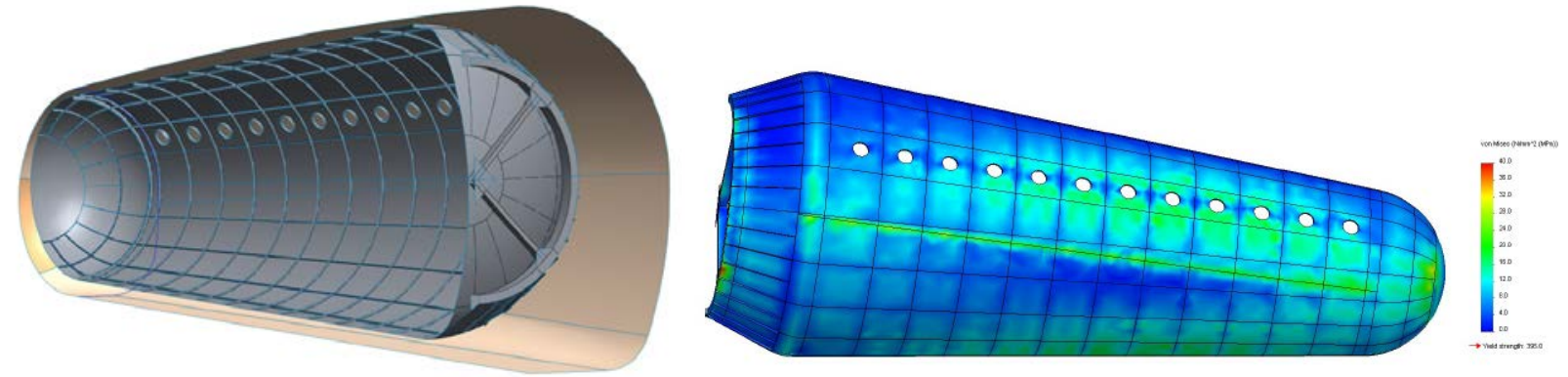

Figure 14: Integration of pressurized passenger cabin inside aerodynamic capsule shell (left) and Von Mises stress distribution in passenger capsule under bending loads [26]

A fundamental requirement for the design of the rescue capsule is its integration in the front section of the passenger stage. The capsule should be separated as easily and quickly as possible. Therefore, it cannot be an integral part of the fuselage structure, however, its upper aft section is conformal with the SpaceLiner's fuselage while the lower side is fully protected by the fuselage bottom structure. The current requirement of capsule separation being feasible at any flight condition and attitude is highly challenging from a technical point of view. Recent analyses revealed some critical issues to be addressed in order to improve the safe functionality of the cabin rescue system. Alternative capsule integration concepts have been proposed and technically analyzed [44]. However, each of the explored design options is linked to severe challenges and drawbacks. Further investigations are necessary to find a promising and reliable system. 
A highly innovative investigation on design options to improve the capsules flight performance after separation is ongoing in the FP7-project HYPMOCES aiming to investigate and develop the technologies in the area of control, structures, aerothermodynamics, mission and system required to enable the use of morphing structures [42, 43]. Inflatable as well as rigid deployable wing options are under study. The baseline design after finishing the first design loop is shown in Figure 15 at left. Similarities and major differences on the lower side and deployable fins in the aft section are visible in comparison to the reference geometry of Figure 13. Note the double instead of previously single bodyflap derived of IXV which is now baseline of the capsule.

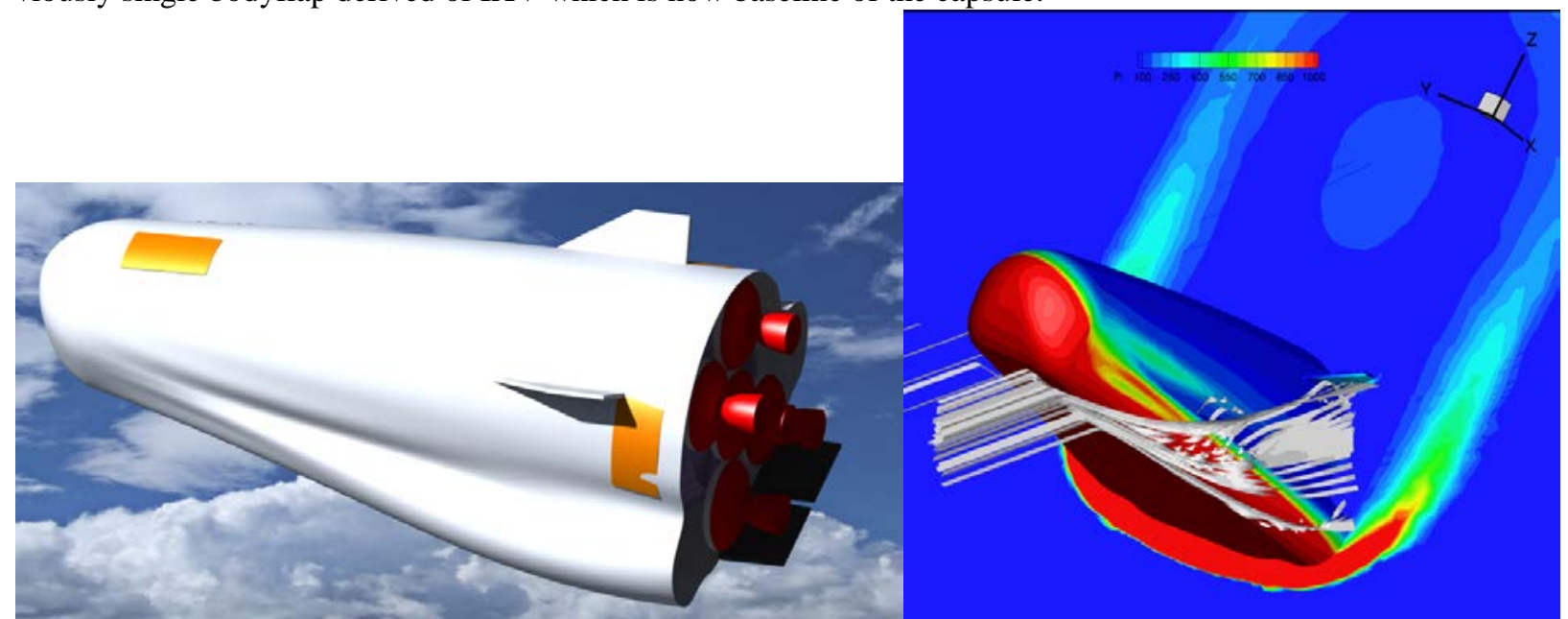

Figure 15: SpaceLiner capsule option with inflatable morphing lower section and deployable fins and CFDsimulation of ONERA

The SpaceLiner passenger capsule with its shape and integration issues is currently in a dynamic design loop. Future evolutions of the SpaceLiner configurations will strongly be influenced by the obtained results.

\section{Thermal protection and active cooling subsystem}

The ambitious Australia to Europe reference mission requires the SpaceLiner passenger stage to accelerate to a maximum speed slightly above $7 \mathrm{~km} / \mathrm{s}$. In the subsequent hypersonic gliding trajectory the vehicle surface at the lower side and leading edges are subject to severe thermal conditions. Maximum calculated radiation adiabatic surface temperatures would reach about $2600 \mathrm{~K}$ and heat fluxes about $2 \mathrm{MW} / \mathrm{m}^{2}$ [47]. An early description of the SpaceLiner's aerothermodynamic challenges and rough sizing of the Thermal Protection System (TPS) for the nominal mission has been described in $[2,15]$. However, the TPS has to withstand several different heat loads according to nominal flight and also for different abort cases. The surface temperatures are calculated under assumption of an adiabatic wall in radiation equilibrium and a fully turbulent flow along the flight path has been assumed for the TPS dimensioning as a conservative assumption [22].

The maximum acceptable temperature for the passive TPS is limited to approximately $1850 \mathrm{~K}$ to be compliant with the reusability requirement. The structure underneath is allowed to heat up to maximum temperatures between 400 $\mathrm{K}$ and $530 \mathrm{~K}$ depending on the selected materials (compare section III-D!). Due to the requirement of reusability, only non-ablative materials are suitable on the SpaceLiner's surface.

This leads to a total TPS mass on the passenger stage (without capsule and tank insulation and system mass margin) between approximately 15.5 tons ( $530 \mathrm{~K}$ substructure temperature) and 24.6 tons (400 K) [47]. This is a significant mass saving compared to the previous SpaceLiner 7-2 TPS layout [24, 26]. Recently an alternative TPS on the vehicle's upper surface (temperature distribution shown in Figure 16) has also been considered, consisting of two layers of a metallic skin. Material data were provided by Dutch Space (Airbus). The TPS tile consists of mainly two layers, a metallic skin (Haynes 230) and thermal insulation (IFI). Haynes 230 is used for all "hot" metallic parts of the TPS and in particular for the skins of the TPS tiles which are directly exposed to the aerothermal heat flux. Although significantly heavier than thermal blankets (in comparison to the use of TABI, a metallic TPS would have an additional mass of approx. $5.9 \mathrm{t}$ [41]) it should be operationally more robust [47]. 


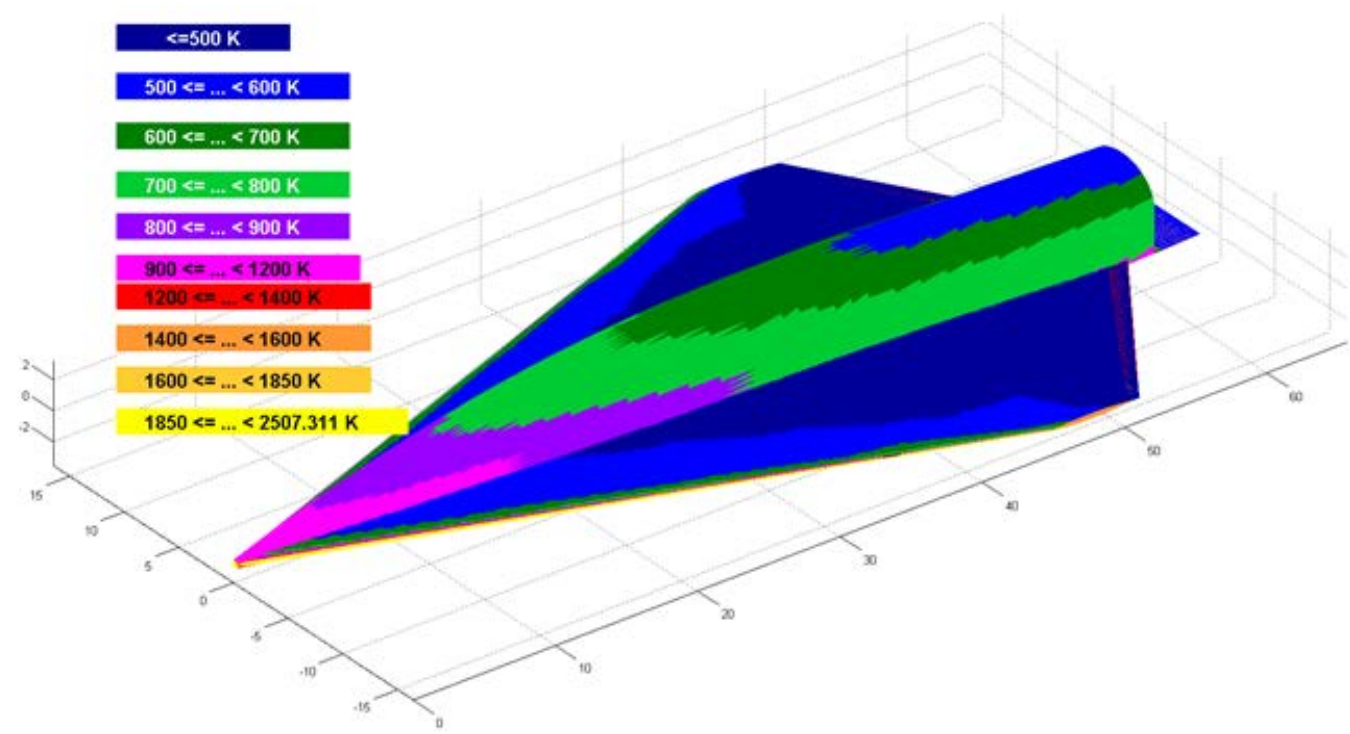

Figure 16: Overall maximum surface temperature areas reached on the upper side of SpaceLiner 7 (considering nominal and abort trajectories) [41]

The heat insulation on the passenger capsule alone, including an ablatable nose, is approximately $4000 \mathrm{~kg}$ [47]. In a similar design procedure the TPS of the reusable booster stage has been defined. Large upper surface areas are to be covered by thermal blankets. The booster's TPS mass reaches approximately 13.9 tons (without cryogenic tank insulation and margins) [47].

In those areas where the heatflux and temperatures exceed acceptable values CMC can withstand, transpiration cooling using liquid water is a potential technical solution [2, 11, 15]. In FAST20XX this innovative method has been experimentally tested in DLR's arc heated facility in Cologne using subscale probes of different porous ceramic materials. The pressure drop of the cooling flow going through the leading edge or nose wall material is no more than 200 or $300 \mathrm{kPa}$.

Although this advanced cooling process is still at a TRL of 3, a first preliminary active cooling pre-design has been executed at DLR-SART for the SpaceLiner geometry. The transpiration of $\mathrm{H}_{2} \mathrm{O}$ is required starting during the final phase of the powered orbiter flight when leading edge temperatures are already becoming excessively high. Approximately $10000 \mathrm{~kg}$ of water are needed for cooling during a nominal mission. A water storage tank system, a feedline manifold including control and check-valves and some bypass and redundancy lines are sized for accommodation inside the SpaceLiner volume. It is interesting to note that already in 1970 TRW studied and predimensioned a somewhat similar system under NASA contract [39].

Besides the overall promising results also some technical challenges of the active transpiration cooling system have been detected in the FAST20XX-investigations. Precise controllability of the water flow through the porous ceramic media has been found difficult [47]. The experiments sometimes were running into over or under supply of water which could not be recovered within the same experimental run. A more sophisticated supply system would be needed in a flight vehicle. However, real flight conditions usually are more complex and demanding than those in a laboratory. Another concern is the fact that the gas flow from the coolant might trigger early boundary-layer transition. As a consequence, some areas of the passive TPS might need to be reinforced.

Therefore, the active transpiration cooling of leading edges and nose is still the reference design option but could once be replaced by other means of active cooling [46, 47]. A more detailed system assessment of the different design choices based on reliable mass estimations should be performed in the next iteration steps.

\section{F. System masses}

With available data of the structural pre-design of both booster and passenger stage, the previously only empirically based estimation relations derived of launch vehicles or hypersonic transport studies could be updated to a new mass 
calculation of increased accuracy. System margins of $14 \%$ (12 \% for propulsion) are added to all estimated mass data as for the previous variants with less detailed design. This is a relatively conservative approach, however, selected in this still early development stage because of this advanced vehicle with ambitious safety and reusability requirements.

The preliminary structural sizing of the booster fuselage resulted in a significant increase in the structural mass of the large integral LH2-tank. Overall stage mass increased to slightly above $200 \mathrm{Mg}$ (Table 4). With moderately reduced propellant loading the structural index of the booster increased to $15.6 \%$ which is probably a realistic value for a large cryogenic reusable stage. Based on available subsystem sizing and empirical mass estimation relationships, the orbiter mass is derived as listed in Table 5. The total fluid and propellant mass includes all ascent, residual, and RCS propellants and the water needed for the active leading edge cooling. The stages' MECO mass is approximately $157.5 \mathrm{Mg}$.

Table 4: Mass data of SpaceLiner 7-3 booster stage

\begin{tabular}{|c|c|c|c|c|c|c|}
\hline $\begin{array}{c}\text { Structure } \\
{[\mathrm{Mg}]}\end{array}$ & $\begin{array}{c}\text { Propulsion } \\
{[\mathrm{Mg}]}\end{array}$ & $\begin{array}{c}\text { Subsystem } \\
{[\mathrm{Mg}]}\end{array}$ & TPS $[\mathrm{Mg}]$ & $\begin{array}{c}\text { Total dry } \\
{[\mathrm{Mg}]}\end{array}$ & $\begin{array}{c}\text { Total } \\
\text { propellant } \\
\text { loading }[\mathrm{Mg}]\end{array}$ & GLOW [Mg] \\
\hline 124.6 & 37.3 & 20.1 & 19.1 & 201 & 1284 & 1485 \\
\hline
\end{tabular}

Table 5: Mass data of SpaceLiner 7-3 orbiter stage

\begin{tabular}{|c|c|c|c|c|c|c|}
\hline $\begin{array}{c}\text { Structure } \\
{[\mathrm{Mg}]}\end{array}$ & $\begin{array}{c}\text { Propulsion } \\
{[\mathrm{Mg}]}\end{array}$ & $\begin{array}{c}\text { Subsystems } \\
\text { including } \\
\text { cabin }[\mathrm{Mg}]\end{array}$ & $\begin{array}{c}\text { TPS [Mg] } \\
\text { (metallic upper } \\
\text { surface) }\end{array}$ & $\begin{array}{c}\text { Total dry } \\
{[\mathrm{Mg}]}\end{array}$ & $\begin{array}{c}\text { Total fluid \& } \\
\text { propellant } \\
\text { loading }[\mathrm{Mg}]\end{array}$ & $\begin{array}{c}\text { GLOW incl. } \\
\text { passengers \& } \\
\text { payload[Mg] }\end{array}$ \\
\hline 56.3 & 10.6 & 46.5 & 26.6 & 140 & 230 & 370 \\
\hline
\end{tabular}

The SpaceLiner 7-3's GLOW reaches now about 1855 Mg (Table 6) for the reference mission Australia - Europe. This relatively large value is still below that of the Space Shuttle STS of more than $2000 \mathrm{Mg}$ and therefore technically within reach. Recent analyses of operationally attractive reference mission trajectories indicate generous performance margins. Further trade-studies, taking into account adverse vehicle or flight conditions, will allow a precise assessment on how far a future SpaceLiner configuration update might be reduced in its size and mass.

\section{Table 6: Mass data of SpaceLiner 7-3 launch configuration}

\begin{tabular}{|c|c|c|}
\hline $\begin{array}{c}\text { Total dry } \\
{[\mathrm{Mg}]}\end{array}$ & $\begin{array}{c}\text { Total } \\
\text { propellant } \\
\text { loading }[\mathrm{Mg}]\end{array}$ & $\begin{array}{c}\text { GLOW incl. } \\
\text { passengers \& } \\
\text { payload }[\mathrm{Mg}]\end{array}$ \\
\hline 341 & 1514 & 1855 \\
\hline
\end{tabular}

\section{G. Nominal trajectory}

Several trajectory options have been traded for the Australia - Europe reference mission. These are all following a standard launch vehicle vertical ascent with an initial azimuth in North-Eastern direction overflying the arctic sea before approaching Europe from the North-Eastern Atlantic. This is the same baseline trajectory which has been established for the SpaceLiner 4 using ASTOS optimizations [14]. Maximum speed of the vehicle is around 7.1 $\mathrm{km} / \mathrm{s}$ at $69 \mathrm{~km}$ and the flight path angle $\gamma$ at MECO is close to $0^{\circ}$ (Figure 17). Then the propulsive phase is directly followed by hypersonic gliding.

An alternative option is a trajectory with a few degrees of $\gamma$ in this point which would result in a ballistic arc duration of a couple of minutes for the SpaceLiner. The vehicle would travel during this phase more than $1000 \mathrm{~km}$ almost outside of the atmosphere at very low drag. However, in order to avoid excessive heatrates, an increased angle-of-attack is subsequently needed at lower altitudes, which has a strongly decelerating effect. 


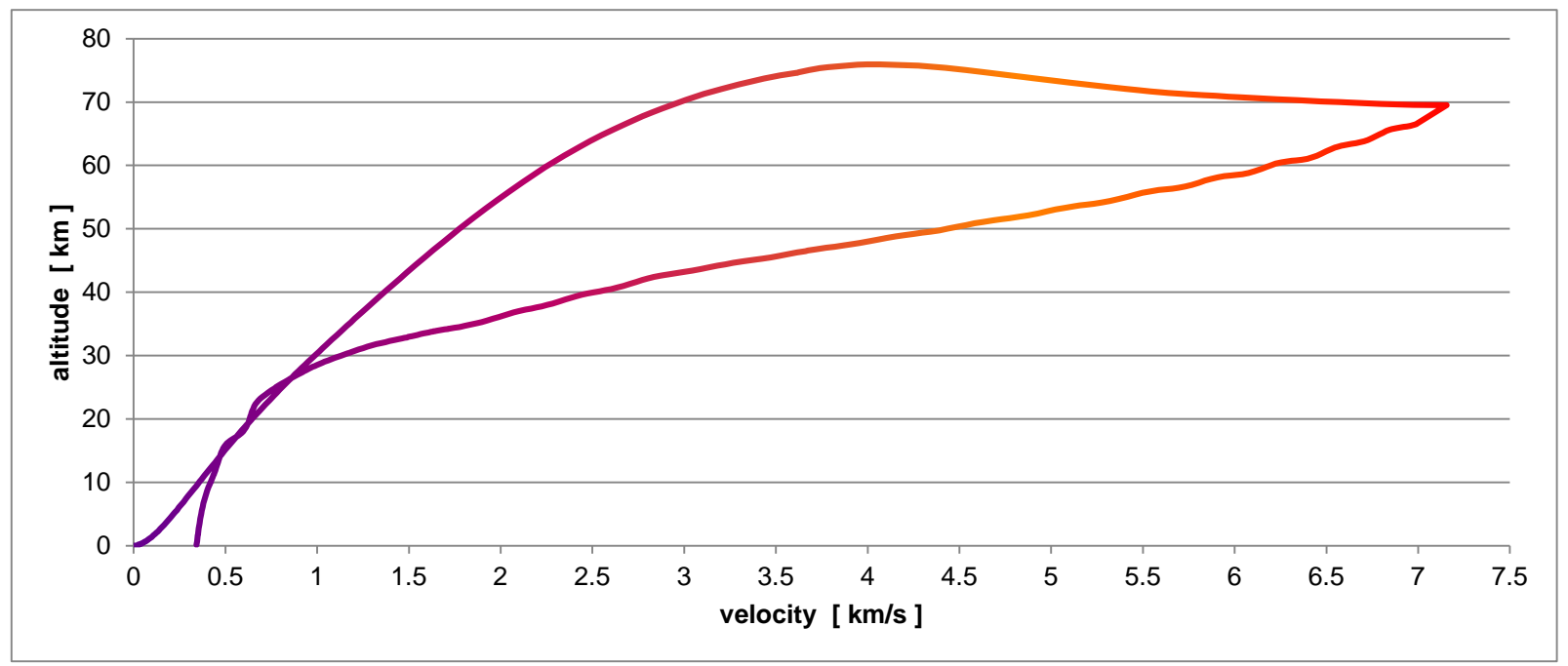

Figure 17: Nominal reference trajectory of SpaceLiner 7-1

A definitive answer on the best trajectory requires detailed system studies taking into account flight path optimization, adapted TPS-sizing, and reliable data on the friction drag in low atmospheric density. The Italian aeronautical research establishment CIRA and University of Naples have been performing DSMC calculations of the SpaceLiner at high altitudes which provide drag coefficients under these conditions [17, 48]. An engineering aerodynamic reference data base is available [28] supporting analyses under realistic conditions.

Flight path as well as groundtrack constraints and demands for operationally interesting launch and landing sites (see following section IV-A) further influence the selection of viable reference trajectories. Such systematic and extensive analyses have been started recently.

\section{Operations, Development Planning and Business Case}

\section{A. Operational Scenario}

The ambitious west-bound Australia - Europe mission has been used as the reference case since the beginning of the SpaceLiner investigations. This flight distance should be served for 50 passengers on a daily basis in each direction. Several other, shorter intercontinental missions exist, which potentially generate a larger market demand. For this reason a SpaceLiner configuration derivative has been studied, which could transport up to 100 passengers [22, 37].

The launch and ascent noise as well as the sonic boom reaching ground are most critical for a viable SpaceLiner operation in the future. The selection of potential SpaceLiner launch and landing sites will likely be influenced by constraints due to generated noise [22]. Therefore, operational scenarios of the SpaceLiner are established taking into account realistic launch- and landing sites as well as groundtracks which are acceptable with respect to sonic boom constraints overflying populated areas and fast accessibility to major business centers.

Conventional existing airports located close to densely populated areas are not suitable for SpaceLiner operations. Three alternative launch and landing site concepts should fit for almost all potential locations [50]:

- On-shore close to sea or ocean

- Artificial island

- Off-shore launch site \& on-shore landing site

All three options are not entirely new and have already been realized in the past. Thus, they also appear feasible in the future. Obviously, these versions have all their advantages and disadvantages. The optimal version depends on the particular location where a spaceport is planned to be built with climate and geographical location playing an important role [50]. Such pre-selection has been performed based on a first systematic assessment on intercontinental high-speed connection options [51] of the SpaceLiner. These analyses are ongoing and preliminary results indicate that the overall performance is not negatively affected by the operational constraints. 


\section{B. Development Planning}

Based on the ECSS standard development logic a dedicated SpaceLiner Master Program Schedule as visible in Figure 18 has been defined.

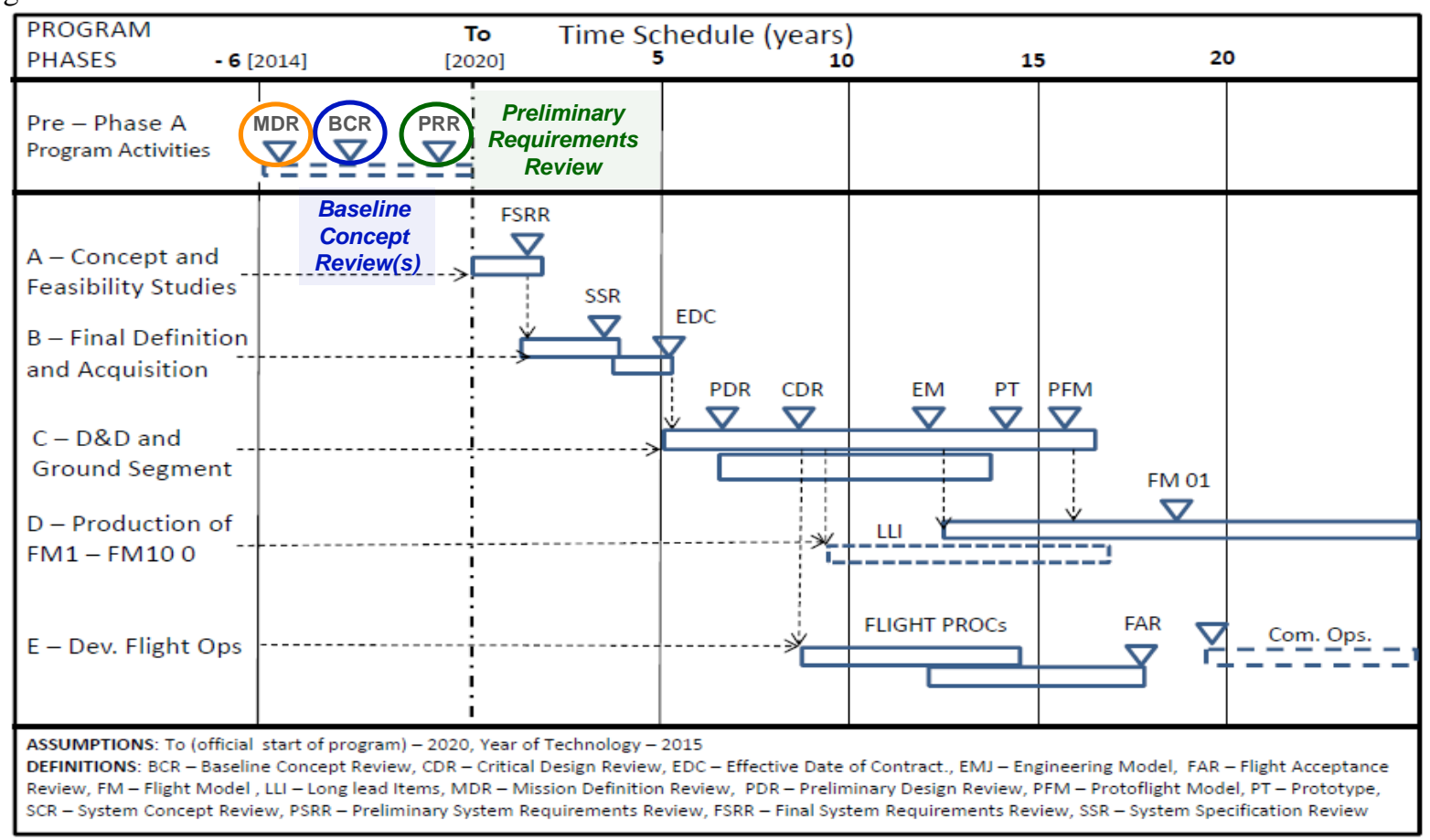

Figure 18: SpaceLiner Development Roadmap [52]

With contribution of B. Madauss, ISU, 2014

Following the SpaceLiner Master Program Schedule of Figure 18, a well-structured development process is initiated. Actual industrial development beginning with Phase A is scheduled to start at T0 in 2020. During the current pre-development and technology maturation phase, running until 2020, a few key milestones and reviews are to be addressed:

- MDR in 2015

- Early concept reviews (“BCR”) or subsystem reviews in 2016ff.

- PRR in approximately 2019

Afterwards - depending on available funding - the technical development of the SpaceLiner will follow in rough estimation this timeline:

- SRR in 2020

- PDR in 2025

- CDR in 2030

First Flight of a SpaceLiner prototype should occur ca. 2035 and subsequently extensive flight testing and the certification process is expected. An operational SpaceLiner high-speed passenger transport system should be reached in $2040+$ at least for one point-to-point destination.

The overall hardware testing and qualification process is extremely demanding compared to all previous launcher projects including the reusable Space Shuttle and Buran systems. The high number of tests is driven by the safety requirements of a passenger transport system. In order to support reliable development cost estimation, some basic data have been selected [52]. All these data are still to be confirmed by a detailed development roadmap but can already give an indication of the necessary effort:

- Engine prototypes (for firing on test stand): 30 (1200 test firings, 40 firings /engine)

- SpaceLiner vehicle prototypes: 6 with a few hundred test flights

- Prototype flight testing and qualification time: 6 years 


\section{Cost Estimation and Business Case}

The SpaceLiner development and operations should one day be funded mostly by private investment. Forms of private public partnerships are other potential options. In any case a reliable estimation of to be expected costs during development, production, and operations is already required early in the technical design process. Using this approach a market oriented development can be performed. A paper has been published [25] giving a detailed description.

The preliminary cost inputs derived from the TransCost calculations were fed into an Orbspace developed Business Case Simulator (BCS) software tool, for the preliminary establishment and analysis of a business case. The combination of the process to establish initial and justifiable development and production cost estimates to use as input for a tool business case simulation tool is considered a solid foundation and methodology for future development of the SpaceLiner LCC assessment. Early results indicate that the SpaceLiner is not only a technically feasible concept but also one for which a viable business case might exist [25, 26].

Recently, more sophisticated analyses of the expected SpaceLiner development and production costs have been parametrically assessed [49]. Previous results are confirmed and sensitivity of data is obtained. An update of the business case simulation based on this research is planned in future work.

Proper and timely project appraisal can dictate if a company's business endeavor succeeds or fails. Before starting a new business case simulation, the appraisal of the innovation 'SpaceLiner' has been assessed, focused on the economic, touristic purpose of the acquisition of gain (space tourism) [53]. Using the qualitative method addressed by the 'House of Quality (HoQ)' and the quantitative procedure of 'Risk Analysis (RA)' a suitable solution has been found for the evaluation. Two questions were addressed: How customer oriented is the SpaceLiner? and Which chances of investment success can be expected?

The HoQ shows how customer-oriented the SpaceLiner is and which characteristics are the most important with regard to the target group. Different sensitivity analyses and the comparison to an already existing A380 airliner delivered a promising customer value [53]. The RA demonstrates the risks and chances of the concept. Revised overall cost estimation and several sensitivity analyses show that the idea of this vehicle is connected to some uncertainties und financial risk, but can also offer great chances. These results are not surprising for an advanced highly innovative concept addressing a new type of market. The quantified data of [53] allow for further optimization in SpaceLiner design and operations.

\section{Conclusion}

The DLR proposed reusable winged rocket SpaceLiner for very high-speed intercontinental passenger transport has further matured in its conceptual design. Research on the vehicle has been performed with support from the EU projects FAST20XX, CHATT, HIKARI and HYPMOCES with several European partners. Assuming advanced but not exotic technologies, a vertically launched rocket powered two stage space vehicle is able to transport about 50 passengers over distances of up to $17000 \mathrm{~km}$ in about 1.5 hours.

The potential intercontinental SpaceLiner missions have been subdivided into three classes of which class 1 is the ambitious Australia - Europe reference flight presented in this paper. The latest iteration step of the SpaceLiner concept is the version 7-3 which is based more and more on preliminary design of different subsystems and vehicle structures. An integrated interdisciplinary design process of the passenger stage has delivered a convergent configuration. The paper presents the latest investigation status on major subsystems like the full-flow staged combustion main engine, the tank-, feed-, crossfeed- and pressurization system, the integrated passenger cabin and rescue capsule, the structural design, and the thermal protection- and active cooling subsystem. An aerodynamic database for early preliminary engineering design work for performance analyses in nominal and off-nominal conditions and assessment of the SpaceLiner's flying qualities is established. The project puts some highly challenging questions addressing hypersonic aerothermodynamics, like safe separation of a capsule and controlled flight in the full Mach-range, in focus of future research. 
Furthermore, early cost estimations have been concluded and business case simulations have been performed. Preliminary results of business assessment, customer appraisal, and investment risk analyses, indicate that the SpaceLiner is not only a technically feasible concept but also one for which a viable business case might exist.

Work on the visionary SpaceLiner concept is gaining momentum in the European aerospace community.

\section{Acknowledgements}

Part of this work was performed within the 'Future High-Altitude High-Speed Transport 20XX' project investigating high-speed transport. FAST20XX, coordinated by ESA-ESTEC, is supported by the EU within the 7th Framework Programme Theme7 Transport, Contract no.: ACP8-GA-2009-233816.

Part of this work was performed within the 'Cryogenic Hypersonic Advanced Tank Technologies' project investigating tank technologies for high-speed transport. CHATT, coordinated by DLR-SART, is supported by the EU within the 7th Framework Programme Theme 7 Transport, Contract no.: ACP1-GA-2011-285117. Further information on CHATT can be found on http://www.chatt.aero

Further, part of the research leading to these results has received funding from the European Union's Seventh Framework Programme FP7/2007-2013 under grant agreement $n^{\circ}$ AAT-2012-RTD-341531 entitled "Hypersonic Morphing for a Cabin Escape System (HYPMOCES)”.

The authors gratefully acknowledge the contributions of Ms. Sarah Lipp, Ms. Mona Carlsen, Ms. Carina Ludwig, Ms. Cecilia Valluchi, Mr. Ryoma Yamashiro, Mr. Izan Peris Marti, Mr. Magni Johannsson, Mr. David Gerson, Mr. Jochen Bütünley, Mr. Aron Lentsch, Mr. Luigi Morsa, Mr. Ola Rasmusson, Mr. Bernd Madauss, Mr. Raffaele Votta, and Mr. Rafael Molina to the preliminary design of the SpaceLiner.

\section{References}

1. Sippel, M., Klevanski, J., Steelant, J.: Comparative Study on Options for High-Speed Intercontinental Passenger Transports: Air-Breathing- vs. Rocket-Propelled, IAC-05-D2.4.09, October 2005

2. Sippel, M., Klevanski, J., van Foreest, A., Gülhan, A., Esser, B., Kuhn, M.: The SpaceLiner Concept and its Aerothermodynamic Challenges, $1^{\text {st }}$ ARA-Days, Arcachon July 2006

3. Sippel, M.; Klevanski, J.: Preliminary Definition of the Supersonic and Hypersonic Airliner Configurations in LAPCAT, AIAA 2006-7984, $14^{\text {th }}$ Spaceplanes Conference, November 2006

4. van Foreest, A., Sippel, M., Klevanski, J., Gülhan, A., Esser, B.: Technical Background and Challenges of the SpaceLiner Concept, $7^{\text {th }}$ International Symposium on Launcher Technologies, Barcelona, Spain, April 2-5, 2007

5. Sippel, M.: Introducing the SpaceLiner Vision, $7^{\text {th }}$ International Symposium on Launcher Technologies, Barcelona, Spain, April 2-5, 2007

6. Sippel, M., van Foreest, A.: Latest Progress in Research on the SpaceLiner High-Speed Passenger Transportation Concept, IAC-07-D2.7.07, September 2007

7. van Foreest, A.; Sippel, M.: The Logistical Challenges of the SpaceLiner Concept, IAA $1^{\text {st }}$ Symposium on Private Human Access to Space, Arcachon May 28-30 2008

8. Sippel, M.: Promising roadmap alternatives for the SpaceLiner, Acta Astronautica, Vol. 66, Iss. 11-12, (2010)

9. Sippel, M.: SpaceLiner - a Visionary Concept of an Ultra Fast Passenger Transport under Investigation in FAST20XX, AIAA 2009-7439, $16^{\text {th }}$ AIAA/DLR/DGLR International Space Planes and Hypersonic Systems and Technologies Conference, Bremen 2009

10. Sippel, M., van Foreest, A.: SpaceLiner Rocket-Powered High-Speed Passenger Transportation Concept Evolving in FAST20XX, IAC-10-D2.4.06, September 2010

11. Van Foreest, A. , Sippel, M.; Gülhan, A.; Esser, B.; Ambrosius, B.A.C.; Sudmeijer, K.: Transpiration Cooling Using Liquid Water, Journal of Thermophysics and Heat Transfer, Vol. 23, No. 4, October-December 2009 
12. Kopp, A.; van Foreest, A., Sippel, M.; Dalenbring, M.; Jarlas, R.: Investigation of Structure for the Hypersonic Transport System SpaceLiner, AIAA 2011-2373, 17 ${ }^{\text {th }}$ AIAA International Space Planes and Hypersonic Systems and Technologies Conference, April 2011

13. Neeb, D., Schwanekamp, T., Gülhan, A.: Preliminary Aerodynamic Shape Optimization of the SpaceLiner by Means of Engineering Methods, AIAA 2011-2299, $17^{\text {th }}$ AIAA International Space Planes and Hypersonic Systems and Technologies Conference, April 2011

14. Sippel, M. van Foreest, A.; Bauer, C.; Cremaschi, F.: System Investigations of the SpaceLiner Concept in

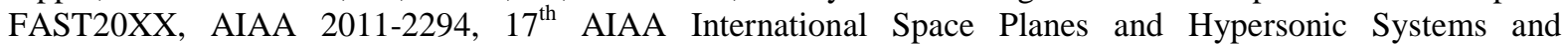
Technologies Conference, April 2011

15. Sippel, M.; van Foreest, A.; Dietlein, I.; Schwanekamp, T.; Kopp, A.: System Analyses Driving Improved Aerothermodynamic Lay-out of the SpaceLiner Configuration, ESA-SP692, May 2011

16. Sippel, M.; Yamashiro, R.; Cremaschi, F.: Staged Combustion Cycle Rocket Engine Design Trade-Offs for Future Advanced Passenger Transport, ST28-5, SPACE PROPULSION 2012, Bordeaux, 7th - 10th May 2012

17. Sippel, M.; Votta, R.: Advanced Launcher Technology Maturation Supported by EU-Aeronautic Research Projects, IAC-12-D2.5.6, Naples, October 2012

18. Sippel, M.; Kopp, A.; Sinko, K.: Advanced Hypersonic Cryo-Tanks Research in CHATT, AIAA2012-5945, 18th AIAA International Space Planes and Hypersonic Systems and Technologies Conference, Tours, September 2012

19. Sippel, M.; Kopp, A.; Mattsson, D.; Freund, J.; Tapeinos, I.; Koussios, S.: Final Results of Advanced CryoTanks Research Project CHATT, 6TH EUROPEAN CONFERENCE FOR AERONAUTICS AND SPACE SCIENCES (EUCASS) 2015, Krakow, July 2015

20. Blanvillain, E.: HIKARI: Joining efforts to prepare Future High Speed Air Transport, $5^{\text {th }}$ International Workshop on Aircraft System Technologies, Hamburg, 24.02.2015

21. Blanvillain, E.: HIKARI: Paving the way towards High Speed Air Transport, AIAA 2015-3676, $20^{\text {th }}$ AIAA International Space Planes and Hypersonic Systems and Technologies Conference, Glasgow, July 2015

22. Sippel, M.; Schwanekamp, T.; Bauer, C.; Garbers, N.; van Foreest, A.; Tengzelius, U.; Lentsch, A.: Technical Maturation of the SpaceLiner Concept, AIAA2012-5850, $18^{\text {th }}$ AIAA International Space Planes and Hypersonic Systems and Technologies Conference, Tours, September 2012

23. Rasmusson, O.: Structural Reference Design of Booster for the SpaceLiner Concept, Ms.Thesis Royal Institute of Technology, Stockholm, October 2012

24. Garbers, N.: Overall Preliminary Design of the Thermal Protection System for a Long Range Hypersonic Rocket-Powered Passenger Vehicle (SpaceLiner), ESA TPS-HS Workshop 2013

25. Trivailo, O.; Sippel, M.; Lentsch, A.; Sekercioglu, A.: Cost Modeling Considerations \& Challenges of the SpaceLiner - An Advanced Hypersonic, Suborbital Spaceplane, AIAA Space2013 conference, San Diego, September 2013

26. Sippel, M.; Schwanekamp, T.; Trivailo, O.; Lentsch, A.: Progress of SpaceLiner Rocket-Powered High-Speed Concept, IAC-13-D2.4.05, IAC2013, Beijing, September 2013

27. Peris Marti, I. : Structural analysis and design of a truss connecting structure for the SpaceLiner booster, SART TN-008/2015, June 2015

28. Schwanekamp, T.; Morsa, L.; Zuppardi, G.; Molina, R.: SpaceLiner 7-2 Aerodynamic Reference Database, SART TN-026/2012, 2013

29. Sippel, M.; Schwanekamp, T.; Ortelt, M.: Staged Combustion Cycle Rocket Engine Subsystem Definition for Future Advanced Passenger Transport, Space Propulsion 2014, Cologne, Germany, May 2014

30. Schwanekamp, T.; Ludwig, C.; Sippel, M.: Cryogenic Propellant Tank and Feedline Design Studies in the Framework of the CHATT Project, 19th AIAA International Space Planes and Hypersonic Systems and Technologies Conference, AIAA Aviation and Aeronautics Forum and Exposition, June 2014

31. Sippel, M.; Klevanski, J.; Kauffmann, J.: Innovative Method for Return to the Launch Site of Reusable Winged Stages, IAF-01-V.3.08, 2001

32. Sippel, M.; Klevanski, J.: Simulation of Dynamic Control Environments of the In-Air-Capturing Mechanism, $6^{\text {th }}$ International Symposium on Launcher Technology 2005, B1.4 
33. Schwanekamp, T.; Bauer, C.; Kopp, A.: The Development of the SpaceLiner Concept and its Latest Progress, $4{ }^{\mathrm{TH}}$ CSA-IAA CONFERENCE ON ADVANCED SPACE TECHNOLOGY, Shanghai, September 2011

34. Bauer, C.; Garbers, N., Johannsson, M.; Lentsch, A.: INVESTIGATIONS OF THE SPACELINER PASSENGER CAPSULE AND VARIOUS ABORT SCENARIOS, DLRK 2012, September 2012

35. Kopp, A.; Garbers, N.; Jarlas, R.: Parametric Structural Analysis for the SpaceLiner, AIAA-5944, $18^{\text {th }}$ AIAA International Space Planes and Hypersonic Systems and Technologies Conference, Tours, September 2012

36. Johnson, T. F.; Gates, T. S., High temperature polyimide materials in extreme temperature environments, AIAA-2001-1214, 42 ${ }^{\text {nd }}$ AIAA/ASME/ASCE/AHS/ASC Structures, Structural Dynamics, and Materials Conference and Exhibit, Seattle, Washington, April 2001

37. Schwanekamp, T.; Bütünley, J.; Sippel, M.: Preliminary Multidisciplinary Design Studies on an Upgraded 100 Passenger SpaceLiner Derivative, AIAA 2012-5808, $18^{\text {th }}$ AIAA International Space Planes and Hypersonic Systems and Technologies Conference, Tours, September 2012

38. Pankhurst, R. C.: N.P.L. Aerofoil Catalogue and Bibliography, MINISTRY OF AVIATION, AERONAUTICAL RESEARCH COUNCIL, REPORTS AND MEMORANDA, R. \& M. No. 3311, 1963

39. Johnston, C. G.; Gomet, A. V.: RADIATIVE, ABLATIVE, AND ACTIVE COOLING THERMAL PROTECTION STUDIES FOR THE LEADING EDGE OF A FIXED-STRAIGHT WING SPACE SHUTTLE, PART V: TRANSPIRATION COOLED HEAT SHIELDS PERFORMANCE, NAS 9-81 66, Houston, 31. DECEMBER 1970

40. Sippel, M.; Schwanekamp, T.: The SpaceLiner Hypersonic System - Aerothermodynamic Requirements and Design Process, 8th European Symposium on Aerothermodynamics for Space Vehicles, Lisbon, March 2015

41. Garbers, N.: Metallic Thermal Protection System for SpaceLiner, SART TN-016/2014, 2014

42. Bonetti, D. et al: Hypersonic Morphing for a Cabin Escape System: Results of First Design Loop, $8^{\text {th }}$ European Symposium on Aerothermodynamics for Space Vehicles, Lisbon 2015

43. Laroche, E.: Aerothermodynamics analysis of the Spaceliner Cabin Escape System modified via a morphing system, $8^{\text {th }}$ European Symposium on Aerothermodynamics for Space Vehicles, Lisbon 2015

44. Bauer, C.; Kopp, A.; Schwanekamp, T.; Clark, V.; Garbers, N.: Passenger Capsule for the SpaceLiner, DLRKpaper, Augsburg 2014

45. Haya Ramos, R. et al: Aerodynamics and Flying Qualities Requirements for a Long-range Transportation System, ${ }^{\text {th }}$ European Symposium on Aerothermodynamics for Space Vehicles, Lisbon 2015

46. Schwanekamp, T.; Mayer, F.; Reimer, T.; Petkov, I.; Tröltzsch, A.; Siggel, M.: System Studies on Active Thermal Protection of a Hypersonic Suborbital Passenger Transport Vehicle, AIAA Aviation Conference, AIAA 2014-2372, Atlanta, June 2014

47. Schwanekamp,T., Garbers, N.; Sippel, M.: Conceptual Design of the SpaceLiner Thermal Protection System, $8^{\text {th }}$ European Symposium on Aerothermodynamics for Space Vehicles, Lisbon 2015

48. Zuppardi, G.; Morsa, L.; Sippel, M.; Schwanekamp, T.: Aero-Thermo-Dynamic Analysis of the SpaceLiner-7.1 Vehicle in High Altitude Flight, Proceedings of the $29^{\text {th }}$ International Symposium on Rarefied Gas Dynamics, 2014, AIP Conf. Proc. 1628, 1268-1276 (2014); doi: 10.1063/1.4902737

49. Trivailo, O.: Innovative Cost Engineering Analyses and Methods Applied to SpaceLiner - an Advanced, Hypersonic, Suborbital Spaceplane Case-Study, PhD Thesis submitted 27.03.2015

50. Lipp, S.; Bauer, C.; Trivailo, O.: Spaceport Concepts and Locations for the SpaceLiner, SART TN-022/2014, October 2014

51. Garg, K.; Schwanekamp, T.: Preliminary investigation and optimization of potential operational flight trajectories for the hypersonic passenger transport concept SL, SART-TN023/2014, 2014

52. Sippel, M.: SpaceLiner Development Roadmap and Technology\&Research Requirements, V1, SART TN014/2014, May 2015

53. Lipp, S.; Trivailo, O.: Innovation appraisal of the SpaceLiner concept, SART TN-005/2015, April 2015

Further updated information concerning the SART space transportation concepts is available at: http://www.dlr.de/SART 